\title{
The role of forcing and internal dynamics in explaining the "Medieval Climate Anomaly"
}

\author{
Hugues Goosse - Elisabeth Crespin - Svetlana Dubinkina • \\ Marie-France Loutre - Michael E. Mann • Hans Renssen • \\ Yoann Sallaz-Damaz • Drew Shindell
}

Received: 2 September 2011 / Accepted: 16 January 2012 / Published online: 4 February 2012

(C) Springer-Verlag 2012

\begin{abstract}
Proxy reconstructions suggest that peak global temperature during the past warm interval known as the Medieval Climate Anomaly (MCA, roughly 950-1250 AD) has been exceeded only during the most recent decades. To better understand the origin of this warm period, we use model simulations constrained by data assimilation establishing the spatial pattern of temperature changes that is most consistent with forcing estimates, model physics and the empirical information contained in paleoclimate proxy records. These numerical experiments demonstrate that the reconstructed spatial temperature pattern of the MCA can be explained by a simple thermodynamical response of the climate system to relatively weak changes in radiative forcing combined with a modification of the atmospheric circulation, displaying some similarities with the positive phase of the so-called Arctic Oscillation, and with northward shifts in the position of the Gulf Stream and Kuroshio
\end{abstract}

H. Goosse $(\bowtie) \cdot$ E. Crespin · S. Dubinkina · M.-F. Loutre · Y. Sallaz-Damaz

Earth and Life Institute, Georges Lemaître Centre for Earth and Climate Research, Université Catholique de Louvain, Chemin du Cyclotron, 2, 1348 Louvain-la-Neuve, Belgium e-mail: hugues.goosse@uclouvain.be

M. E. Mann

Department of Meteorology and Earth and Environmental Systems Institute, Pennsylvania State University,

University Park, PA, USA

H. Renssen

Section Climate Change and Landscape Dynamics,

Department of Earth Sciences, Vrije Universiteit Amsterdam,

Amsterdam, The Netherlands

D. Shindell

NASA Goddard Institute for Space Studies,

New York City, NY, USA currents. The mechanisms underlying the MCA are thus quite different from anthropogenic mechanisms responsible for modern global warming.

Keywords Paleoclimate - Last millennium - Medieval Climate Anomaly · Climate modelling · Data assimilation · Atmospheric and ocean dynamics · Radiative forcing

\section{Introduction}

Proxy temperature reconstructions indicate that the Medieval Climate Anomaly (MCA, roughly 950-1250 AD) was warm in many parts of the world (e.g., Hughes and Diaz 1994; Mann et al. 2008, 2009; Esper and Frank 2009; Frank et al. 2010; Ljungqvist 2010; Graham et al. 2011). Natural radiative forcing associated with quiescent volcanic activity and relatively high solar output may have contributed to large-scale warmth (e.g. Crowley 2000). The solar forcing may also have modified the large-scale atmospheric circulation, inducing stronger mid-latitude westerlies in winter and further warming in substantial regions of the mid-latitude continents (e.g., Shindell et al. 2001, 2003). In addition, the internal variability of the system, purely driven by its own dynamics, can also be responsible for some of the reconstructed changes, in particular at regional scale (Goosse et al. 2005a; Servonnat et al. 2010).

When driven by estimates of past natural and anthropogenic forcings, models tend to produce warmer conditions during the MCA than during the colder "Little Ice Age" (LIA roughly 1400-1700 AD). The models, however, generally underestimate in magnitude the regional changes observed in the reconstructions or fail to coincide in timing with them (e.g., González-Rouco et al. 2003; 
Goosse et al. 2005a; Ammann et al. 2007; Jungclaus et al. 2010; Servonnat et al. 2010; Swingedouw et al. 2011; González-Rouco et al. 2011). This disagreement could be related to uncertainties in the forcing estimates or in the dynamics of the models that would fail in reproducing the adequate response to those forcings (e.g. Goosse et al. 2005b; Osborn et al. 2006). This could also be related to the internal variability of the system as a model cannot simulate the observed time evolution of the climate state if it is not constrained directly by the observations, for instance through data assimilation.

The goal of data assimilation is to combine information coming from both simulations and observations, taking into account their uncertainties, in order to have results compatible with all the elements (e.g. Talagrand 1997). Data assimilation is relatively new in paleoclimatology (see Widmann et al. 2010 for a recent review of the application of data assimilation to the climate of the past millennium). Our goal here is to apply this technique to provide additional insights into the processes that may underlie the patterns of climate change during the MCA. To do so, we perform simulations with the LOVECLIM climate model (Goosse et al. 2010) using a so-called "particle filter" (van Leeuwen 2009; Dubinkina et al. 2011) that constrains model results to follow the signal provided by an annual mean surface temperature reconstruction based on a global proxy data network (Mann et al. 2009). Consequently, the central variable in our discussion is also the annual mean temperature, analyzing the simulated states obtained through data assimilation to interpret the mechanism responsible for the reconstructed changes. In particular, we focus our attention on the extra-tropical Northern Hemisphere, a data-rich region with a well-defined MCA signature. We thus acknowledge that, in this first study devoted to the past millennium at this temporal and spatial scale, we will investigate only one element of the MCA since we will not discuss important characteristics such as the seasonality of the changes, the connections between the tropics and the extra-tropics and the variations in the hydroclimate (e.g., Seager et al. 2007, Jones et al. 2009, Burgman et al. 2010, Graham et al. 2011).

The paper is organized as follows. The methodology, including the models used, the proxy based reconstruction, the data assimilation technique and the experimental design, is described in Sect. 2. The results are then presented in Sect. 3. Section 3.1 discusses the general characteristics of the temperature changes in the LOVECLIM model. The mechanisms responsible for those changes are then analysed in Sect. 3.2. There, we also discuss in more detail some of the hypotheses suggested up to now to explain the MCA that were only briefly mentioned in the introduction. In Sect. 3.3, a special focus is given to the change in the heat balance of the Earth between the MCA and the LIA. In order to consider the various processes that may have played a role in the MCA-LIA transition, including those not well reproduced in LOVECLIM, we analyze complementary simulations performed with the coupled atmosphere-ocean climate model GISS-ER in Sect. 3.4. This allows a deeper analysis of the response of the atmospheric circulation to the forcing. The role of the forcing in the temperature changes between the MCA and the LIA is then compared to the one observed during the recent decades in Sect. 3.5. In addition to the information provided on the MCA itself, this also demonstrates the validity of our approach in a well studied period such as the twentieth century characterized by large variations in the forcing. Finally, conclusions are given in Sect. 4.

\section{Description of the models, the proxy based reconstruction, and the data assimilation method}

\subsection{Proxy-based reconstruction}

In the data assimilation experiments, we make use of a large-scale surface temperature reconstruction spanning the past 1,500 years based on a global network of more than a thousand proxy records (primarily tree ring, ice core, coral, speleothem, and sediment records), as described in Mann et al. (2009). Those records cover nearly all the globe but with a higher density on northern hemisphere continents. The reconstruction follow the RegEM climate field reconstruction approach that has been tested thoroughly using synthetic proxy networks derived from long-term forced climate model simulations (Mann et al. 2007). As the target of the reconstruction is annual mean temperature, this methodology calibrates the proxy network against the spatial information contained within the instrumental annual mean surface temperature over an overlapping (1850-1995) period. Uncertainties in the reconstructions are then estimated from the residual unexplained variance in statistical validation exercises (Mann et al. 2008, 2009). This, for instance, shows that the skill of the reconstruction is quite stable through time. As the reconstruction was produced at the decadal timescale, a similar filtering is applied to our simulations (see below) before performing any analysis, using an 11-year Butterworth filter.

\subsection{The climate model LOVECLIM}

LOVECLIM 1.2 (Goosse et al. 2010) is a three-dimensional Earth system model of intermediate complexity whose components representing the atmosphere, the ocean, the sea ice, and the land surface (including vegetation) are activated here. The atmospheric component is ECBilt2 (Opsteegh et al. 1998), a quasi-geostrophic model with T21 
horizontal resolution (corresponding to about $5.6^{\circ}$ by $5.6^{\circ}$ ) and 3 levels in the vertical. The ocean component is CLIO3 (Goosse and Fichefet 1999), which consists of an ocean general circulation model coupled to a comprehensive thermodynamic-dynamic sea-ice model. Its horizontal resolution is of $3^{\circ}$ by $3^{\circ}$, and there are 20 levels in the ocean. ECBilt-CLIO is coupled to VECODE (Brovkin et al. 2002), a vegetation model that simulates the dynamics of two main terrestrial plant functional types, trees and grasses, as well as desert. Its resolution is the same as in ECBILT.

\subsection{The particle filter}

The particle filter (e.g., van Leeuwen 2009) used in the data assimilation experiments is implemented as explained in Dubinkina et al. (2011). First, an ensemble of 96 simulations (called 'particles' or ensemble members) is initialized for year $501 \mathrm{AD}$ by adding to a single model state small noise in the atmospheric streamfunction. Since the motion in the atmosphere is chaotic, such a perturbation of the atmospheric streamfunction guarantees a sufficiently wide spread of the ensemble on a time scale of a few days at most. Previous experiments (Goosse et al. 2006; Dubinkina et al. 2011) have shown that 96 particles provide a good sample of the large-scale variability of the system while being affordable for simulations with data assimilation covering several centuries. Each particle is then propagated in time by the climate model. After 1 year, the likelihood of each particle is computed from the difference between the proxy-based reconstruction of annual mean temperatures interpolated on the model grid and the simulated ones on all available points northward of $30^{\circ} \mathrm{N}$. This region is selected as it is the focus of our study and because the skill of the model is much higher in the extra-tropics than in the tropical regions (Goosse et al. 2010). The particles are then resampled according to their likelihood, i.e. to their ability to reproduce the signal derived from the proxy records, as in Liu and Chen (1998). The particles with low likelihood are stopped, while the particles with a high likelihood are copied a number of times proportional to their likelihood in order to keep the total number of particles constant throughout the period covered by the simulations, the new weight of each particle being equal to one. A small noise is again added in the atmospheric streamfunction of each copy to obtain different time developments for the following year. The entire procedure is repeated sequentially every year until the final year of calculation. Except for the small perturbations applied at each resampling step, the model dynamics is thus fully respected by the methodology, allowing us to analyze the physical process responsible for the changes in a consistent way. The trajectory selected by the filter could even, in theory, be obtained in a single run without data assimilation covering the full period of interest. The probability of such an event is, however, virtually zero. In any case, it is in practice impossible to launch a number of simulations without data assimilation that is large enough to have a reasonable chance to find one that is close to the reconstructed changes over the whole past millennium, justifying the use of the particle filter.

The likelihood is based on a Gaussian probability density (see van Leeuwen 2009; Dubinkina et al. 2011 for the exact formulation). The error covariance matrix used to compute this likelihood takes into account observation errors and the error of representativeness (i.e., the error related to the fact that data and models are not able to represent the same spatial structures because of grid and sub-grid scale variability present in the data and the lack of observations in some regions to display a true mean on the size of the model grid, see Kalnay 2003). We assume that observation errors are uncorrelated in space and that the error of representativeness is proportional to the covariance between surface temperature at different locations in a long control run of LOVECLIM (Sansó et al. 2008). The evaluation of the likelihood is performed on spatially smoothed fields in which the features with scales smaller than $4,000 \mathrm{~km}$ are efficiently removed in order to emphasize the contribution of large-scale structures. This smoothing is taken into account in the estimate of the errors.

\subsection{Experimental design of the simulations with LOVECLIM}

The simulations are performed over the period 501-2000 AD. They are driven by both natural forcings (orbital, volcanic and solar) and anthropogenic forcings (changes in greenhouse gas concentrations, in sulfate aerosols and land-use) in the same way as in Goosse et al. (2010). The total solar irradiance changes follow the reconstruction of Muscheler et al. (2007), scaled to provide an increase of $1 \mathrm{~W} \mathrm{~m}^{-2}$ between the Maunder minimum (late seventeenth century) and the late twentieth century (i.e. a radiative forcing of about $0.2 \mathrm{~W} \mathrm{~m}^{-2}$ ) and the long-term changes in orbital parameters are derived from Berger (1978). External forcing due to explosive volcanism is prescribed according to Crowley et al. (2003). The evolution of greenhouse gas concentrations is imposed from a compilation of ice core records as explained in Goosse et al. (2005a). The influence of anthropogenic (AD 1850-2000) sulfate aerosols is represented through a modification of surface albedo (Charlson et al. 1991). The forcing due to anthropogenic land-use changes (affecting surface albedo, surface evaporation and water storage) is applied as in Goosse et al. (2005a), following Ramankutty and Foley (1999). In order to take into account the 
uncertainties in the forcing, a random component is added to those natural and anthropogenic forcings for each member of the simulations with data assimilation. This random component, which is uncorrelated in time and between the particles, follows a Gaussian probability distribution with a standard deviation of $0.4 \mathrm{~W} \mathrm{~m}^{-2}$. The initial conditions in $501 \mathrm{AD}$ are obtained from the results of a transient simulation over the period 1-500 AD driven by the same forcings starting from a quasi-equilibrium simulation corresponding to the forcing estimates for year 1 AD.

We first perform an ensemble of 10 simulations without data assimilation starting from those initial conditions in $501 \mathrm{AD}$. In the standard simulations with data assimilation (referred to as STD when any confusion with another experiment can occur), which starts from the same initial conditions, the uncertainty of the reconstruction (Mann et al. 2009) is assumed to be of $0.5^{\circ} \mathrm{C}$. In addition to this standard experiment, several sensitivity experiments have been performed (Table 1) to illustrate the discussion proposed in Sect. 3. In the first group of simulations, we modify some parameters of the experimental design chosen in STD. In Norandom, no additional forcing is applied, while the one in Random 0.8 is obtained from a distribution with a standard deviation of $0.8 \mathrm{~W} \mathrm{~m}^{-2}$ instead of $0.4 \mathrm{~W} \mathrm{~m}^{-2}$ in STD. In Uncertain0.7, we assume an uncertainty of the reconstruction of $0.7^{\circ} \mathrm{C}$ instead of $0.5^{\circ} \mathrm{C}$ in STD. In the second group of experiments, we do not simulate the full climate of the past millennium but only constrain the model to follow the atmospheric circulation anomalies obtained in STD during the MCA (CirculMCA) and during the LIA (CirculMCA). In those experiments, no forcing change is applied.

\subsection{GISS-ER coupled atmosphere-ocean model simulations}

In addition to the simulation performed with LOVECLIM, we analyze results from an ensemble of 6 climate simulations using the coupled atmosphere-ocean climate model GISS-ER without data assimilation, as in Mann et al. (2009). This model has a more comprehensive representation of the atmospheric dynamical and physical processes than LOVECLIM. Its results will thus be used in Sect. 3.4 to analyze in more detail the response of the atmospheric circulation to the solar forcing.

Following a control run to establish stable initial conditions, six transient runs extend from 850 to 1900 C.E. Solar forcing is applied across the ultraviolet, visible and infrared spectrum based on scaling the spectral variation versus total irradiance as seen in modern satellite observations. The total irradiance through time is based on the time series of Bard et al. (2007) derived from South Pole ice core ${ }^{10} \mathrm{Be}$ data and takes into account a small long-term geomagnetic modulation (Korte and Constable 2005) and a polar enhancement factor. The amplitude is scaled to give a top-of-the-atmosphere incoming irradiance change of $2.2 \mathrm{Wm}^{-2}$ between the Maunder Minimum and the late twentieth century. This is twice the amplitude of previous studies or models (Wang et al. 2005; Shindell et al. 2006), and is chosen to provide a larger signal and test the response to a more extreme forcing. It is equivalent to

Table 1 Description of the standard experiment and of the sensitivity experiments performed to illustrate the causes of temperature changes during the MCA

\begin{tabular}{|c|c|c|}
\hline Acronym & Description & Goal of the experiment \\
\hline STD & $\begin{array}{l}\text { Standard experiment with data assimilation using natural and } \\
\text { anthropogenic forcings and an additional forcing selected from a } \\
\text { random distribution with a standard deviation of } 0.4 \mathrm{~W} \mathrm{~m}^{-2}\end{array}$ & General analysis of the MCA-LIA transition \\
\hline Norandom & $\begin{array}{l}\text { Experiment with data assimilation using natural and anthropogenic } \\
\text { forcings but without any additional forcing }\end{array}$ & Analysis of the role of the additional forcing \\
\hline CirculMCA & $\begin{array}{l}\text { LOVECLIM is constrained using data assimilation to follow } \\
\text { the geopotential height simulated in the simulation with data } \\
\text { assimilation (STD) during the MCA (950-1250). A constant } \\
\text { pre-industrial forcing is applied in this experiment }\end{array}$ & $\begin{array}{l}\text { Analysis of the influence of the circulation changes on } \\
\text { the temperature difference between the MCA and the }\end{array}$ \\
\hline CirculLIA & $\begin{array}{l}\text { LOVECLIM is constrained using data assimilation to follow } \\
\text { the geopotential height simulated in the simulation with data } \\
\text { assimilation (STD) during the LIA (1400-1700). A constant } \\
\text { pre-industrial forcing is applied in this experiment }\end{array}$ & LIA \\
\hline Random0.8 & $\begin{array}{l}\text { Experiment with data assimilation using natural and anthropogenic } \\
\text { forcings and an additional forcing selected from a random } \\
\text { distribution with a standard deviation of } 0.8 \mathrm{~W} \mathrm{~m}^{-2} \text { instead } \\
\text { of } 0.4 \mathrm{~W} \mathrm{~m}^{-2}\end{array}$ & Analysis of the role of the additional forcing \\
\hline Uncertain 0.7 & $\begin{array}{l}\text { Experiment with data assimilation but assuming an uncertainty } \\
\text { of the proxy-based-reconstruction of } 0.7^{\circ} \mathrm{C} \text { instead of } 0.5^{\circ} \mathrm{C}\end{array}$ & $\begin{array}{l}\text { Test of the sensitivity of the results to the estimation } \\
\text { of the uncertainty of the proxy-based-reconstruction }\end{array}$ \\
\hline
\end{tabular}


$0.39 \mathrm{~W} \mathrm{~m}^{-2}$ radiative forcing between the Maunder Minimum and the late twentieth century, and about half that between the MCA and LIA. The model includes the ozone response to solar irradiance variations, which is parameterized from the results of prior GISS modeling using a full atmospheric chemistry simulation (Shindell et al. 2006) for computational efficiency. The ensemble mean results are analyzed using time periods within (or very near) the MCA and LIA periods selected in the reconstruction that maximized the solar forcing: 1125-1275 for the MCA, 1650-1750 for the LIA.

\section{Results}

\subsection{Temperature simulated during the past millennium}

LOVECLIM simulations without data assimilation yield hemispheric-mean temperature histories similar to those observed in other simulations employing a similar forcing
(Ammann et al. 2007; Jungclaus et al. 2010). The mean of the ensemble of simulations also agrees well with proxy surface temperature reconstructions (Mann et al. 2009) of the past six centuries, but it fails to capture the warmer conditions of the earlier MCA interval (Fig. 1a). Nevertheless, the reconstruction generally lies in the range provided by the ensemble of simulations (not shown) that, in addition to the forced response estimated through the ensemble mean, also takes into account the internal variability simulated by the model.

The data assimilation strongly improves the agreement over this earlier interval by constraining the model to respond in a way that matches the reconstructed patterns of temperature change. The improvement is also present during the more recent past leading to a decadal correlation between the mean simulation with assimilation and instrumental record (Brohan et al. 2006) of $r=0.95$ ( $p<0.01$ ) over the 1850-2000 interval of overlap, compared to a correlation of 0.84 for the ensemble mean of simulations without data assimilation. This simulation with
Fig. 1 Temperature changes between the MCA and the LIA. a Anomaly of annual mean temperature $\left({ }^{\circ} \mathrm{C}\right)$ averaged over the region $30^{\circ} \mathrm{N}-60^{\circ} \mathrm{N}$ in the reconstruction of Mann et al. (2009) (blue), in the mean of 10 simulations with LOVECLIM without data assimilation (red) and in simulation with data assimilation (green). The reference period is $1850-1980$. The time series have been filtered using an 11-year Butterworth filter to emphasize decadal and longer timescales. The uncertainty ranges (2 standard deviations) are shown for both the reconstruction (violet) and simulations with assimilation (light green, the overlap between the two uncertainty ranges is thus in dark green; the range is not shown for simulations without assimilation). b Annual mean surface temperature difference between MCA (950-1250) and LIA (1400-1700) in model simulation with data assimilation and $\mathbf{c}$ in the reconstruction of Mann et al. (2009). (Note: The color scale is different in $\mathbf{b}, \mathbf{c}$ because it has been independently chosen to highlight the large-scale structure of the changes in each case.)
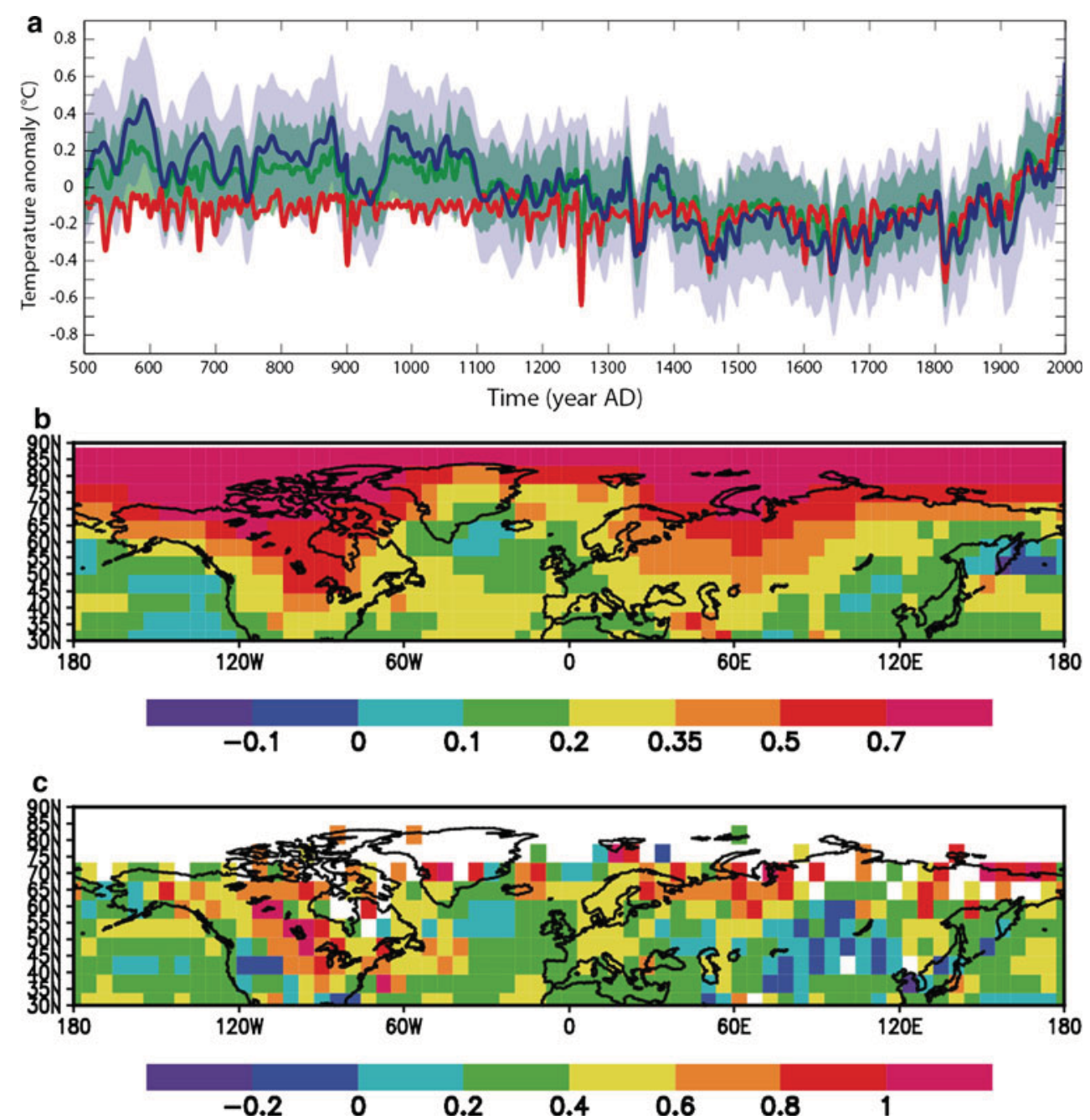
data assimilation, however, does not quite reproduce the level of warmth seen in the reconstruction over the interval prior to $\mathrm{AD} 1100$. This is perfectly compatible with the data assimilation technique that assumes an error in the reconstruction itself and thus has no reason to force the model to give results identical to the one of the reconstruction.

The effect of data assimilation can be illustrated by analyzing the temperature distribution in the simulation with data assimilation, in the simulation without data assimilation and by comparing them with the reconstruction and its uncertainties (Fig. 2). For the first part of the simulation (e.g., the years 1000-1010, Fig. 2a), the simulation with data assimilation has its peak lying between the one of the simulation without data assimilation and the reconstruction. It is thus shifted towards higher temperatures compared to the simulation without data assimilation leading to a distribution displaying a larger overlap with the range of the reconstruction. In a period when the simulation without data assimilation has a mean close to one of the reconstruction, as for the years $1650-1660$
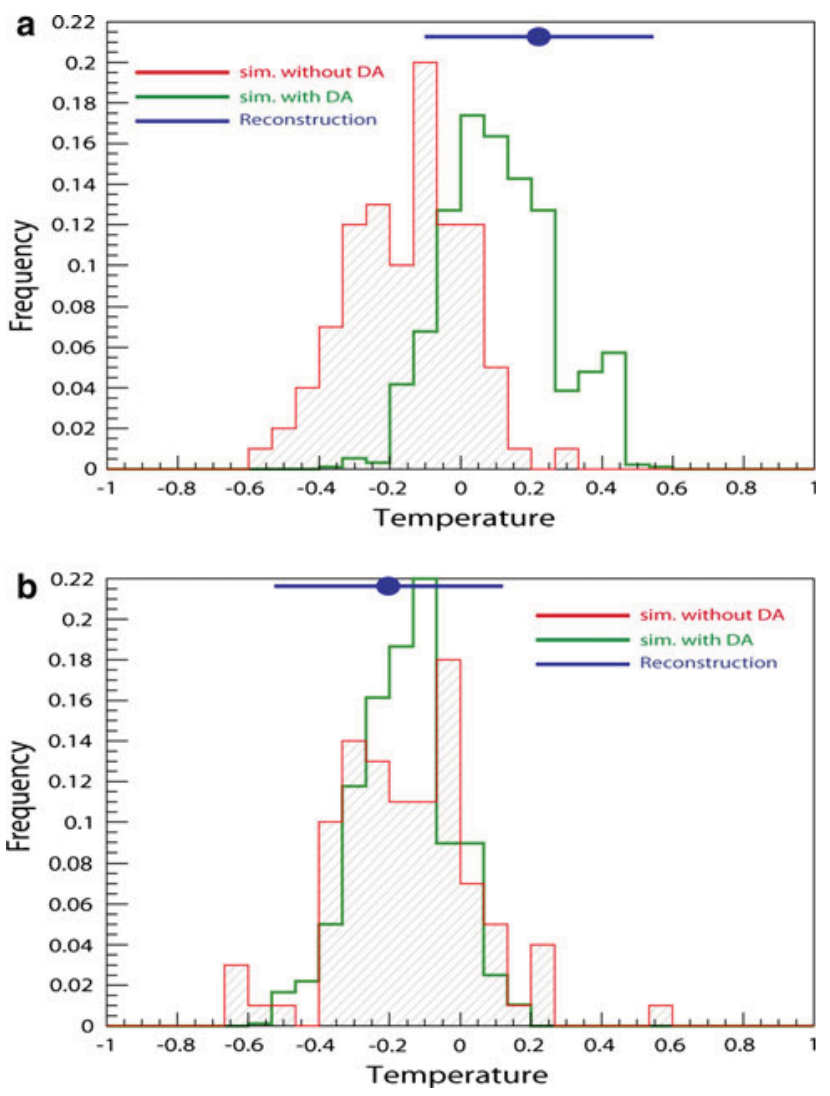

Fig. 2 Distribution of annual mean surface temperature anomaly averaged over the area $30^{\circ} \mathrm{N}-60^{\circ} \mathrm{N}$ for a the period $1000-1010$ and b 1650-1660 in simulations without data assimilation (red) and with data assimilation (green) compared to the reconstruction in blue, including its error estimate ( 2 standard deviations)
(Fig. 2b), the distribution of the simulation with data assimilation has just a sharper peak than the one without data assimilation, the mean being less affected. Data assimilation helps thus to reduce the uncertainties on model results for this period.

A useful way to measure the relative MCA warmth is through the difference with the LIA. Frank et al. (2010), for example, defines a MCA-LIA difference using the LIA interval 1601-1630 and MCA interval 1071-1100, finding a relative hemispheric-mean MCA warmth of $0.38^{\circ} \mathrm{C}$, which falls between the greater $0.44^{\circ} \mathrm{C}$ warmth based on the Mann et al. (2009) reconstruction and the lesser warmth of $0.33^{\circ} \mathrm{C}$ found in our simulation with data assimilation for the same periods. Note, however, that taking a slightly different interval for characterizing the LIA (i.e. $1620-1650$ ) leads to a larger difference of $0.37^{\circ} \mathrm{C}$ in our simulations with data assimilation.

More interesting, however, is the regional pattern of the MCA-LIA surface temperature difference (Fig. 1b, c). In both the reconstruction and the simulation with data assimilation, notable warmth is evident in North Western Russia and in the centre of the American continent, with little relative warmth or even slight cooling over Eastern Asia and parts of the North Atlantic southeast of Greenland.

\subsection{Causes of the temperature changes}

in the simulation with data assimilation

We can now investigate the causes of the complex pattern of MCA warmth. Firstly, the warmer conditions are partly due to the natural and anthropogenic forcings applied in all our simulations. It is illustrated by simulations without data assimilation that display a response to this forcing characterized by a general warming over the continents and smaller changes over the oceans (Fig. 3a). This pattern represents a classical response to a large-scale forcing (e.g., Hegerl et al. 2000) and can be explained by relatively simple thermodynamic processes, the circulation changes in LOVECLIM for the ensemble mean of the simulations without data assimilation being very small.

Secondly, in addition to this radiative forcing, the particle filter can select among a random distribution the forcing that leads to the best agreement with the reconstruction. In our experiment with data assimilation, this induces a slightly stronger forcing during the MCA $\left(+0.07 \mathrm{~W} \mathrm{~m}^{-2}\right)$ and a weaker one during the LIA $\left(-0.06 \mathrm{~W} \mathrm{~m}^{-2}\right)$ (Fig. 4). It is interesting to note that, although the additional forcing imposed to each particle is uncorrelated in time (see Sect. 2.4), the final forcing displayed in Fig. 4 has a clear time correlation which is derived from the methodology itself and not from any a priori assumption. 

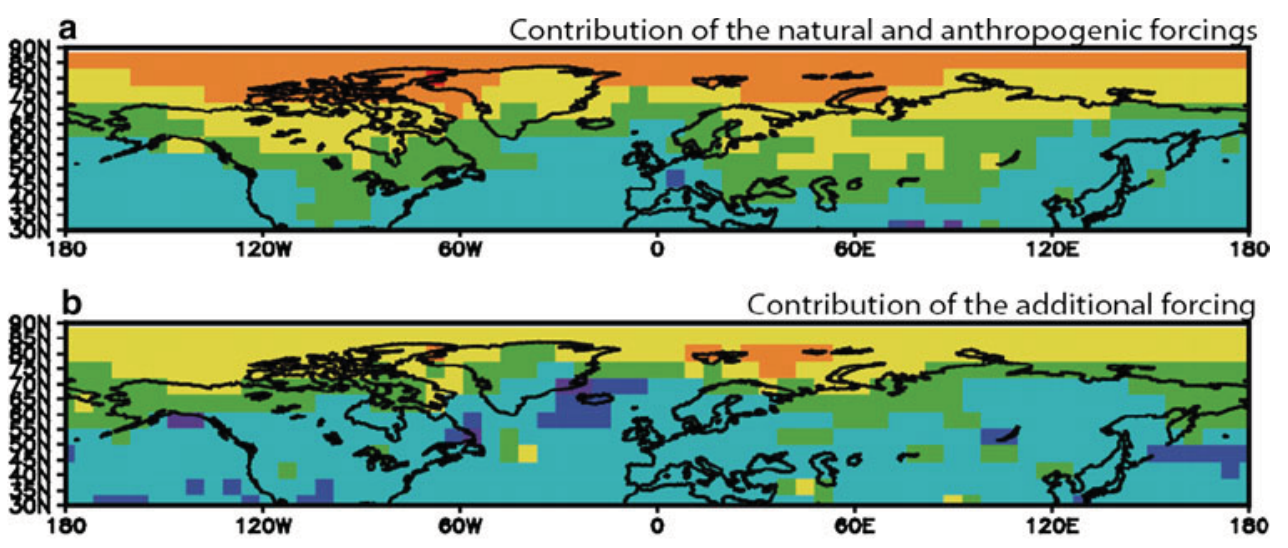

C

Contribution of the circulation changes
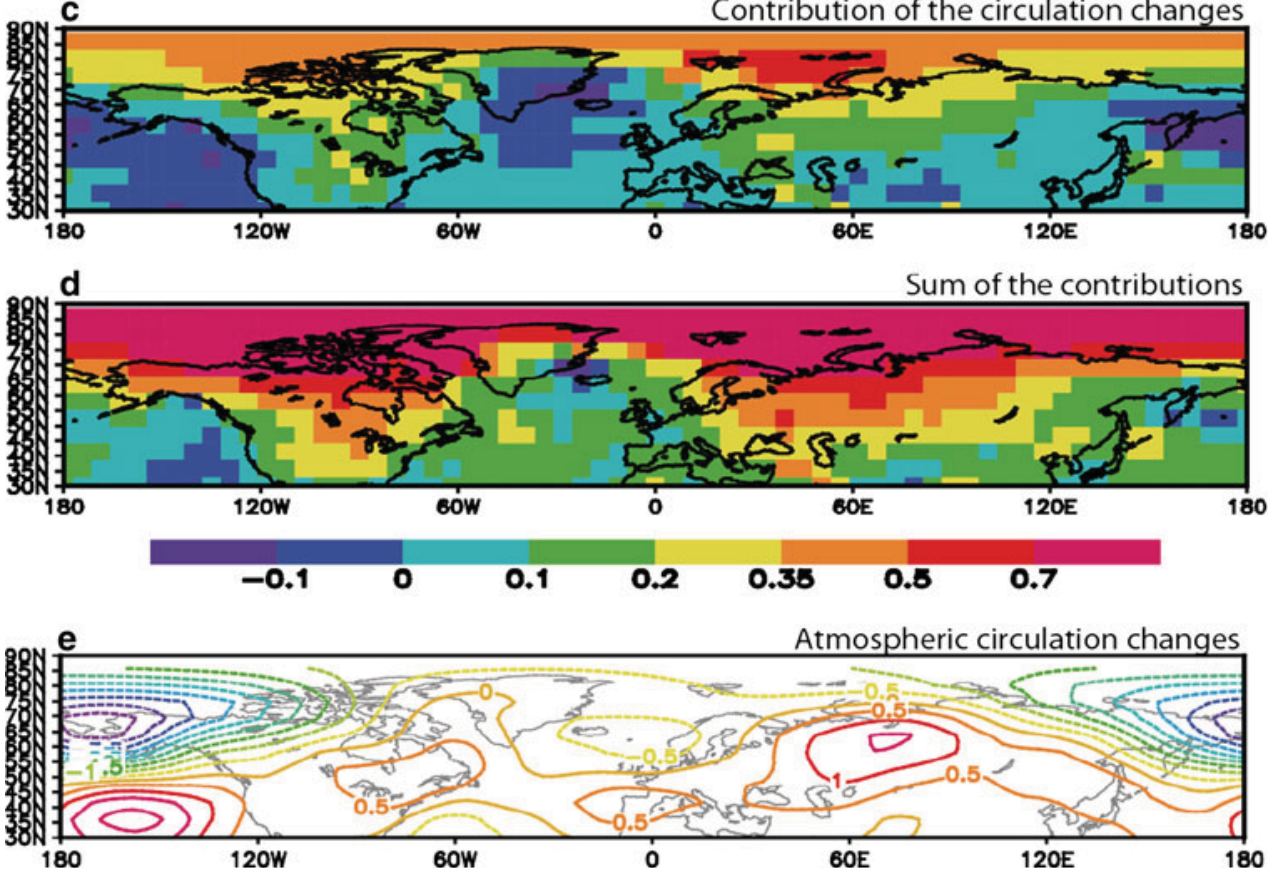

Fig. 3 Causes of the temperature changes between the MCA (950-1250) and the LIA (1400-1700). a Difference of annual mean surface temperature $\left({ }^{\circ} \mathrm{C}\right)$ between the MCA and LIA in an ensemble of model simulations without data assimilation driven by the same natural and anthropogenic forcings as the simulation with data assimilation. b Temperature difference between the MCA and LIA in the standard experiment with data assimilation (STD) minus the one obtained in an experiment with data assimilation in which no additional random forcing is applied (Norandom). $\mathbf{c}$ The difference in annual mean surface temperature (in ${ }^{\circ} \mathrm{C}$ ) between two sensitivity

We have evaluated the contribution of this additional forcing in our standard experiment with data assimilation (STD) by making the temperature difference between the MCA and LIA in STD minus the one of a sensitivity experiment with data assimilation in which no additional random forcing is applied (Norandom, Table 1). It shows that the additional forcing also contributes to a small warming (Fig. 3b). This leads in the simulation with data assimilation to a total effect of the forcing corresponding to experiments is shown: in the first one, LOVECLIM is constrained using data assimilation to follow the geopotential height simulated in the simulation with data assimilation during the MCA (CirculMCA); in the second one, LOVECLIM is constrained to follow the geopotential height simulated in the simulation with data assimilation during the LIA (CirculLIA). d Sum of the fields displayed in ac. e Annual mean difference in geopotential height at $800 \mathrm{hPa}$ (in m) between MCA and LIA in model simulation with data assimilation (STD)

about $60 \%$ of the temperature change between the LIA and the MCA averaged over the region $30^{\circ} \mathrm{N}-60^{\circ} \mathrm{N}$.

Thirdly, the data assimilation also implies dynamic changes in atmospheric circulation, associated with a dipolar pattern of anomalous low (high) surface pressure at high (low) latitudes in the MCA relative to the LIA (Fig. 3e). These changes in geopotential height between the two 300-year periods selected to represent the MCA and the LIA are relatively modest, corresponding to $1-3 \%$ 


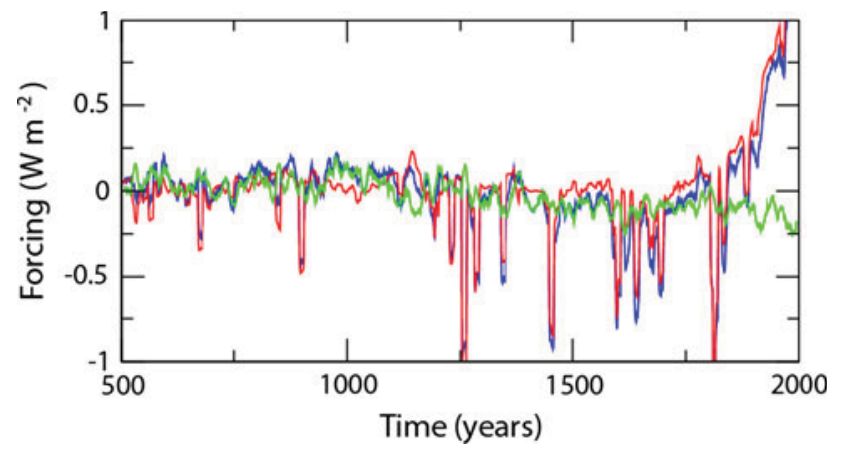

Fig. 4 Changes in the radiative forcing applied at the tropopause in the simulation without data assimilation induced by natural and anthropogenic forcings (red), in the standard simulation with data assimilation (blue) and the difference between them (green). The green curve represents thus the additional random forcing selected by the particle filter in order to have the best agreement between the model results and the proxy-based temperature reconstruction. The time series have been filtered using an 11-year Butterworth filter

of the climatological gradients in the model (Goosse et al. 2010). Nevertheless, as illustrated by comparing two simulations, the first one being constrained using data assimilation to follow the geopotential height simulated in STD during the MCA (CirculMCA) while the second one follows the geopotential height simulated in STD during the LIA (CirculLIA), this atmospheric pattern induces significant temperature changes (Fig. 3c). The temperature increase is large at mid and high latitudes, in particular over the Barents Sea, Northeast Europe and Canada, while a cooling is simulated over the North Atlantic and in Eastern Asia because of northerly winds there. The mechanisms responsible for this temperature pattern are relatively standard and have, for instance, been widely studied in the framework of the NAO (e.g., Wallace et al. 1995; Hurrel 1995; Wanner et al. 2001). In addition to the effect of the meridional wind component mentioned above, the circulation changes are also associated with an enhanced heat transport from ocean to land in many regions. The ocean is thus generally cooling, and the land is mostly warming. Because of the lower inertia of the latter, the magnitude of the surface change is larger over the continents resulting in mean temperature increase. Nevertheless, because of the coarse resolution of our model, the contrast between land and ocean is not clearly expressed in coastal areas: some regions close to an ocean, such as parts of the Western America and Western Europe, are behaving more like the ocean itself than like continental areas.

We do not expect a perfect linear combination of the different contributions. Nevertheless, when the effect of this atmospheric pattern (Fig. 3c) is combined with the one of the changes in the natural and anthropogenic forcings
(Fig. 3a) as well as with the one of the additional forcing (Fig. 3b), the main characteristics of the reconstructed change (Fig. 1c) and thus also of the simulation with data assimilation (Fig. 1b) are well reproduced (Fig. 3d). This shows that, on the basis of Fig. 3, we are able to explain the major characteristics of the temperature changes in our simulation with data assimilation.

The annual mean changes in geopotential height mainly reflect the winter signal (Fig. 5a), variations in summer being much weaker. This winter pattern is not strictly annular but has clear similarities with the positive phase of the Arctic Oscillation (AO, also referred as the Northern Annual Mode)/North Atlantic Oscillation (NAO) which has been proposed to play a strong role in the observed changes during the MCA (Shindell et al. 2001; Shindell et al. 2003; Trouet et al. 2009; Mann et al. 2009). The changes are not confined to the Atlantic sector and, in fact, the dipole is stronger over the Pacific sector both in LOVECLIM and in previous simulations with the climate model GISS-ER (Mann et al. 2009). This characteristic is also present in the AO (defined here as the first principal component of the geopotential height at $800 \mathrm{hPa}$ over the region northward of $30^{\circ} \mathrm{N}$ ) simulated by LOVECLIM (Fig. 5b) and represents a bias compared to the observed pattern seen in many models (e.g. Miller et al. 2006; see also the GISS-ER results discussed in Sect. 3.4). When analysing the probability distribution of the AO in the model a clear shift towards its positive phase is seen during the MCA compared to the LIA (Fig. 5c, d). The difference in geopotential height displays some differences compared to the AO itself, but this result demonstrates that a significant part of the winter circulation changes in our simulations can be interpreted as a modification in the distribution of the AO.

Associated with the modification of the atmospheric circulation discussed above, significant changes in the oceanic near-surface circulation are found between the MCA and the LIA. A clear intensification and northward shift of the subpolar gyre during the MCA are simulated in the Pacific resulting in a large warming off the North coast of Japan (Fig. 6a). A northward shift of the Gulf Stream system is also simulated for the MCA in our standard simulation with data assimilation resulting in a warming off the east coast of North America between $35^{\circ} \mathrm{N}$ and $45^{\circ} \mathrm{N}$ (Fig. 6b). This is consistent with some past studies that have argued for a potential role for such changes in the position or intensity of the near-surface oceanic currents in the West Atlantic and Pacific in long-term climate variability (Frankignoul et al. 2001; Lund et al. 2006; Kwon et al. 2010; Swingedouw et al. 2011).

The intensification of the gyre in the Pacific is perfectly compatible with the intensification of the winds there. This is confirmed by the similar changes obtained by comparing 
Fig. 5 a Winter mean (defined here are the cold half year i.e. November to April) difference in geopotential height at $800 \mathrm{hPa}$ (in $\mathrm{m}$ ) between MCA and LIA in model simulation with data assimilation (STD). b The spatial pattern associated with the first principal component of the winter mean geopotential height at $800 \mathrm{hPa}$ in STD, representing the Arctic Oscillation in LOVECLIM. The probability density function (pdf) of this mode for the MCA (red) and the LIA (blue) and, d the difference between those two pdfs
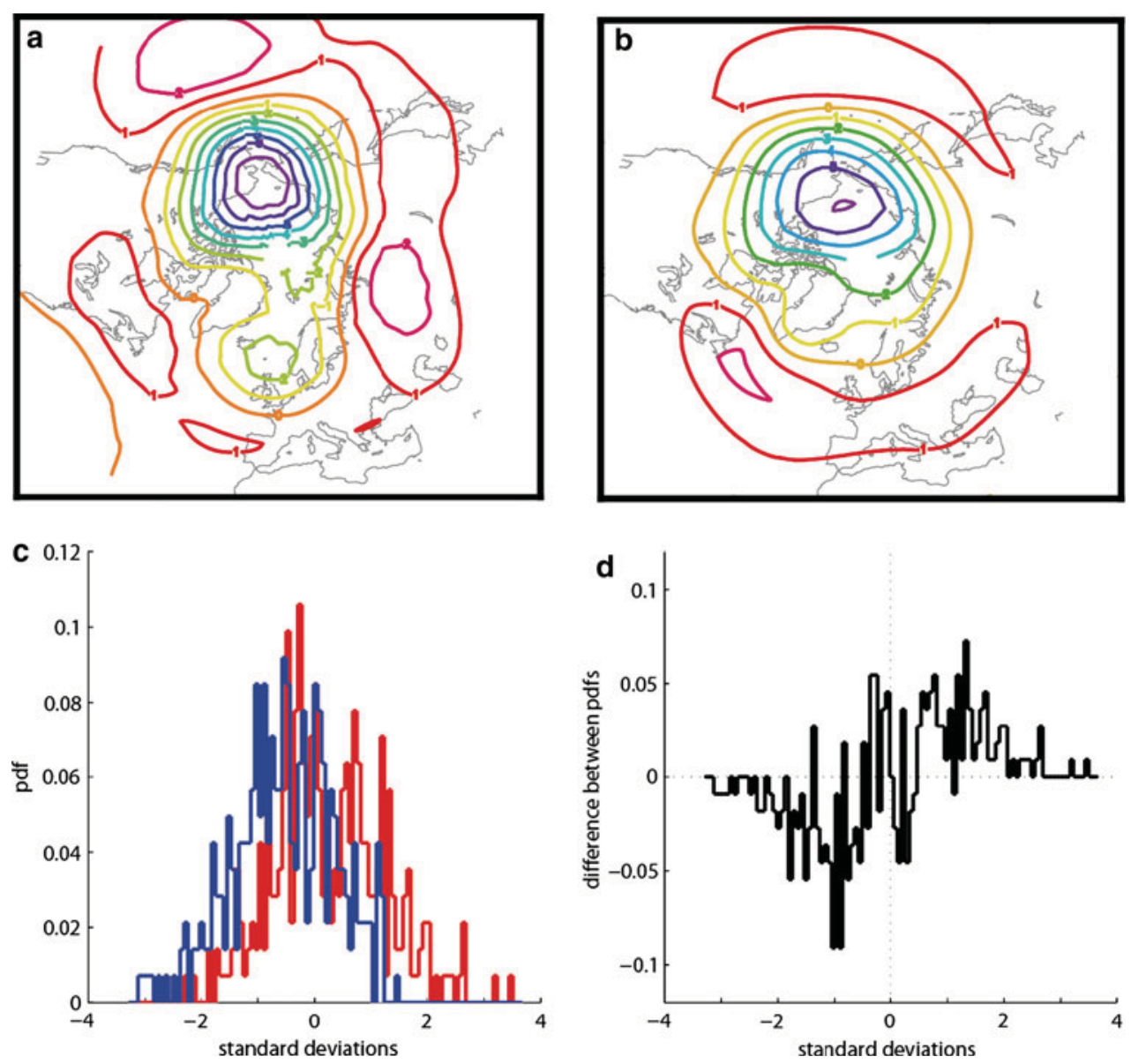

CirculMCA and the CirculLIA (not shown). Besides, the changes in the North Atlantic appear to be more complex, and their link with the wind forcing is less straightforward. Nevertheless, as coarse resolution models such as LOVECLIM have trouble to adequately represent the subtle dynamics of western boundary currents (e.g., Kwon et al. 2010), the mechanisms responsible for the changes in currents in the North Atlantic will not be discussed in more detail here.

The changes in oceanic meridional circulation appear to play a smaller role in the transition between the MCA and the LIA in our experiments with data assimilation. In addition to clear decadal and multidecadal variations, the maximum of the Meridional Overturning Circulation in the North Atlantic displays only a modest reduction of $0.3 \mathrm{~Sv}$ during the MCA relative to the LIA (Fig. 7). This decrease is classical in models during the MCA (e.g. Swingedouw et al. 2011) and, more generally, as a response to a warming (Gregory et al. 2005). It induces a slightly reduced northward heat transport in the Atlantic during the MCA and thus a weak negative feedback on the temperature change, not a positive one that could explain the simulated warming.

\subsection{Changes in the heat balance between the MCA and the LIA}

Additional information on the mechanisms responsible for the temperature changes between the MCA and the LIA can be obtained by analysing the heat balance during those two periods. The net incoming solar radiation at the top of the atmosphere in tropical regions in the standard simulation with data assimilation is about $0.3 \mathrm{~W} \mathrm{~m}^{-2}$ higher during the MCA than during the LIA (Fig. 8a). This is close to the difference in total radiative forcing at the tropopause between those two periods $\left(0.28 \mathrm{~W} \mathrm{~m}^{-2}\right.$, see Fig. 4), illustrating the weak feedback on shortwave flux in LOVECLIM in the tropics (Goosse et al. 2010). The changes between the MCA and the LIA increase in absolute value with latitude, reaching about $0.9 \mathrm{~W} \mathrm{~m}^{-2}$ close to the Pole. This characteristic appears even stronger when analysing the relative changes of the net incoming solar radiation as it varies from an increase of $0.1 \%$ at the Equator to $0.25 \%$ at $50^{\circ} \mathrm{N}$ and more than $1 \%$ at high latitudes (Fig. 8b). This amplification of the response at high latitudes is mainly due to lower surface albedo values caused by the reduction of the snow cover 
Fig. 6 Changes in ocean currents and temperature averaged over the top $100 \mathrm{~m}$ of the ocean a in the North Pacific and $\mathbf{b}$ in the North Atlantic. The difference of annual mean temperature (colors, $\left.{ }^{\circ} \mathrm{C}\right)$ and velocity (vectors, in $\mathrm{m} / \mathrm{s}$, scaling below the figure) between MCA (950-1250) and LIA (1400-1700) in model simulation with data assimilation is shown

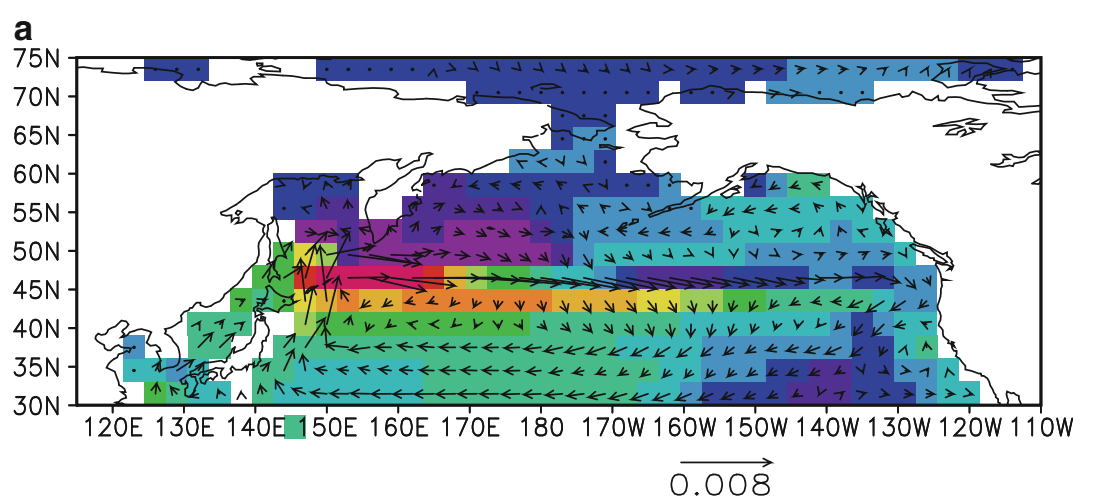

0.5 0.45 0.4 0.35 0.3 0.25 0.2 0.15 0.1 0.05 0 $-0.05$

\section{$\overrightarrow{0.008}$}

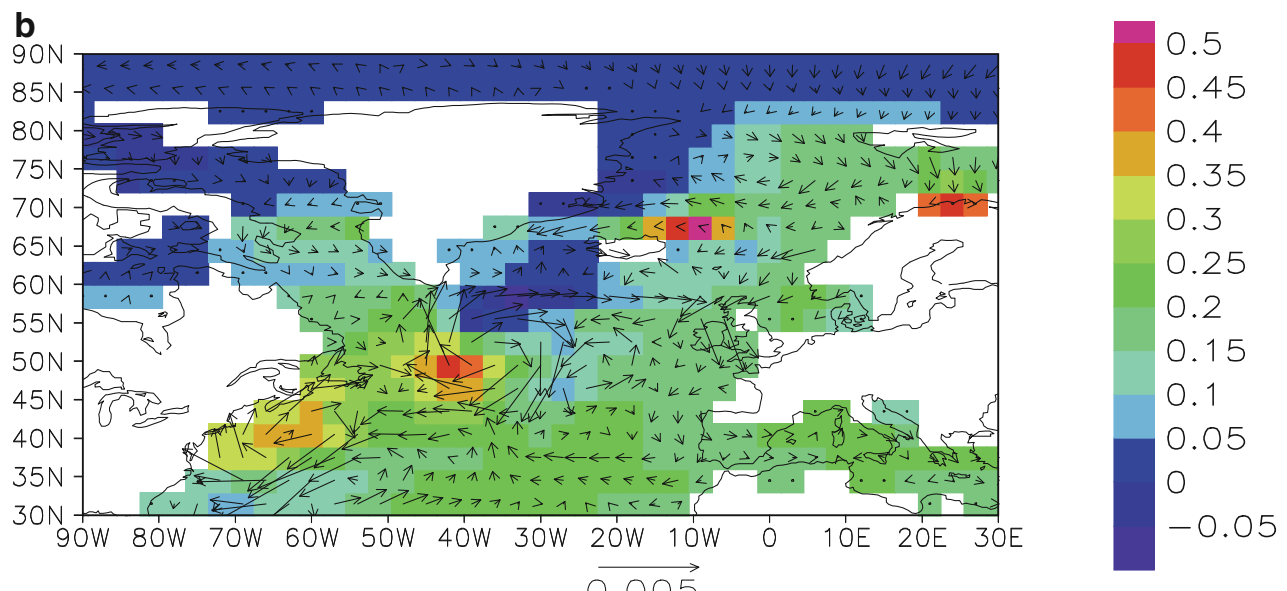

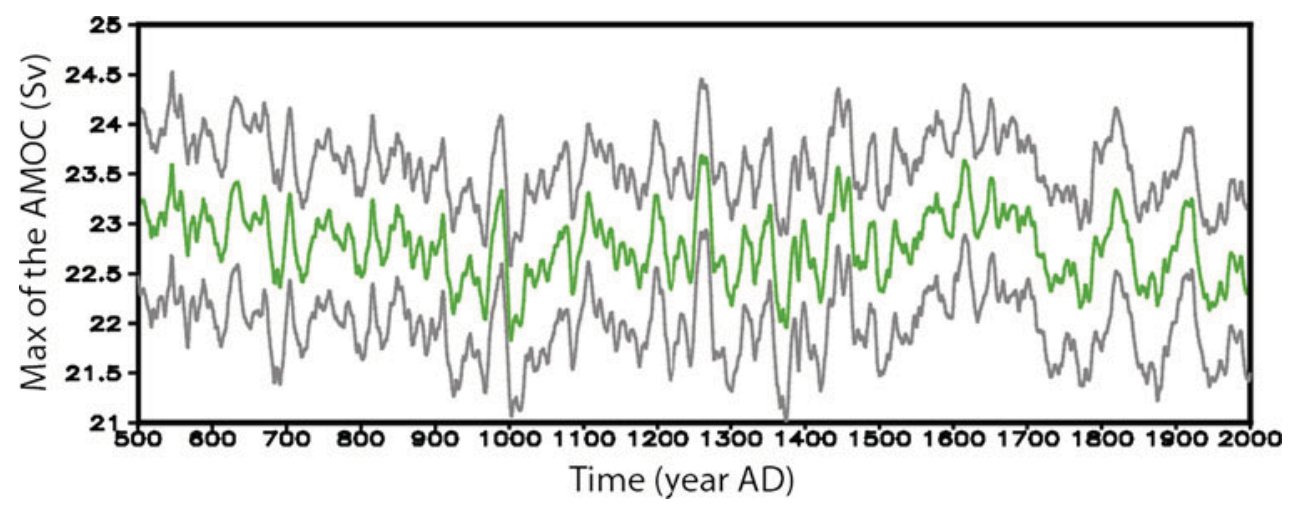

Fig. 7 Maximum of the overturning circulation in the North Atlantic (in $\mathrm{Sv}$ ) in simulations with data assimilation. The green line is the best estimate and the grey lines are this best estimate plus and minus two standard deviations of the ensemble. The time series have been filtered using an 11-year Butterworth filter. This maximum of the overturning circulation is a standard measure of the magnitude of the

over land and sea ice melting at the ice edge during the MCA. The associated increase in surface solar radiation appears particularly large in the Barents Sea, in Northern Russia, and Northern Canada where marked temperature changes were also noticed. In those regions, the surface net solar radiation can be more than $1 \mathrm{~W} \mathrm{~m}^{-2}$ higher in meridional circulation in ocean models defined as the maximum in the North Atlantic of the two dimensional (depth-latitude) streamfunction obtained by performing the integral of the velocity between the eastwest boundaries of the oceanic basin and from the surface to the depth considered

annual mean during the MCA than during the LIA (Fig. 8c).

The larger net incoming solar radiation is nearly perfectly compensated by the increase in the outgoing longwave radiation in the same latitude band. There is thus no additional imbalance at the top of the atmosphere 
Fig. 8 Changes in the heat balance at the top of the atmosphere between the MCA and the LIA. a Zonal mean of the difference in annual mean net incoming solar radiation at the top of the atmosphere $\left(\mathrm{W} \mathrm{m}^{-2}\right.$ ) between the MCA (950-1250) and the LIA (1400-1700) in the standard model simulation with data assimilation (red), of the outgoing longwave radiation at the top of the atmosphere (green) and of the imbalance between incoming and outgoing radiations (blue). b Relative change in the zonal mean of the annual mean net incoming solar radiation at the top of the atmosphere between the MCA and the LIA. c Difference in annual mean net solar radiation at the surface $\left(\mathrm{W} \mathrm{m}^{-2}\right)$ between the MCA and the LIA
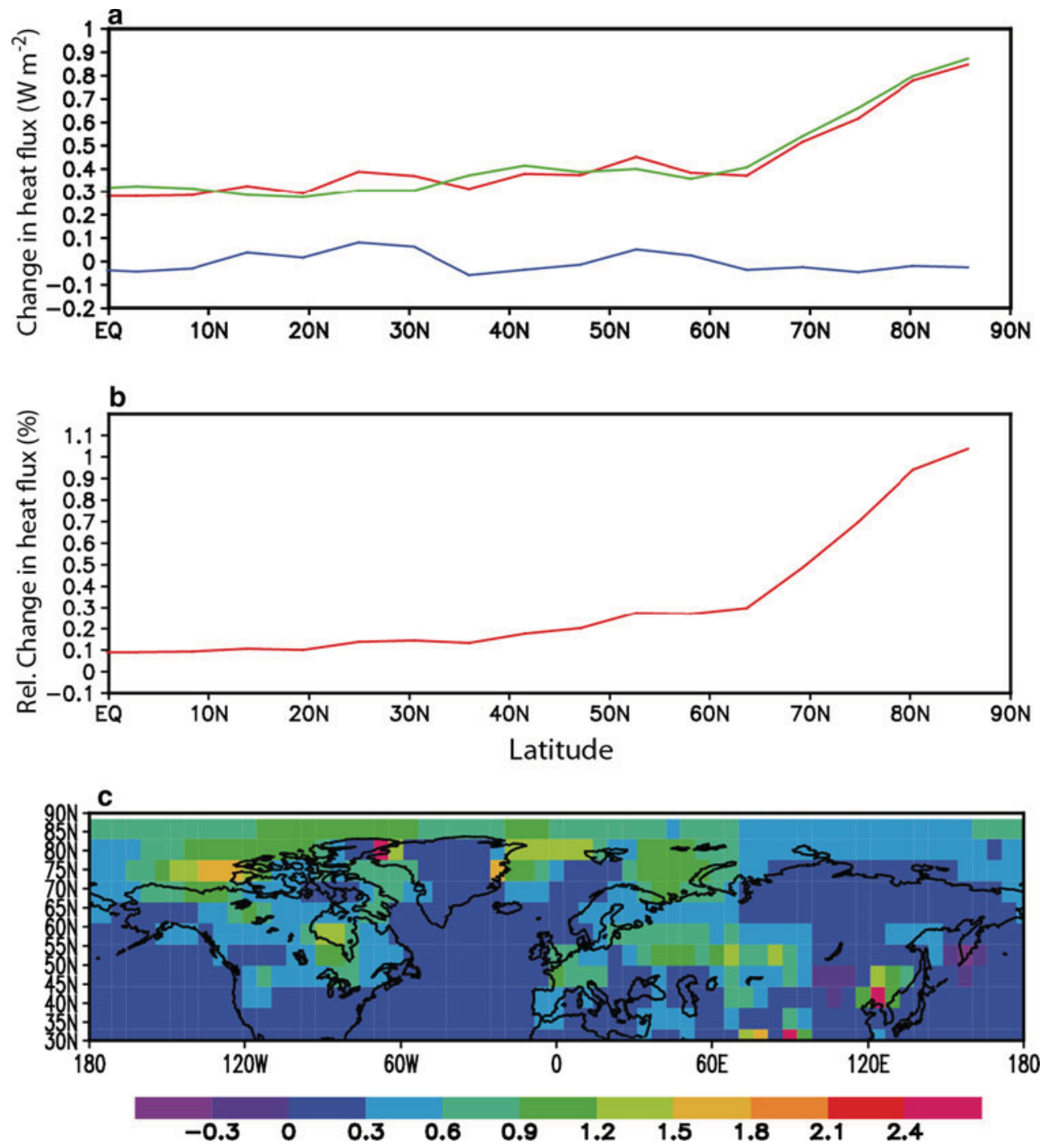

that would require changes in the meridional heat transport. In a consistent way, oceanic and atmospheric meridional heat transports remain more or less similar between the LIA and the MCA in our experiments (not shown). The role of the changes in oceanic and atmospheric circulations have thus either a regional effect, as discussed above for the currents close to the western boundaries of the oceans, or have an influence on the zonal atmospheric transport, in particular because of enhanced exchanges between the land and the oceanic domains. We should, however, remind that our model has a coarse resolution in the atmosphere and is thus not able to account well for potential changes in the transport by transient eddies that play a dominant role in the meridional heat exchanges at mid latitudes. The situation is even worse in the ocean where the effect of those eddies is parameterized in a relatively simple way (Goosse et al. 2010). It would thus be useful to check if our conclusions remain valid in high resolution models representing more accurately those processes.

Besides, the circulation changes still have an indirect impact on the heat balance. As they induce a warming in many continental areas and in the Arctic, they contribute to the changes in surface albedo. This is illustrated in CirculMCA and CirculLIA. Although no modification of the radiative forcing is applied in those experiments, the surface solar radiation is higher in the warmer regions and lower in the colder regions in response to the circulation changes, resulting in a net increase in the net incoming solar radiations at mid and high latitudes (Fig. 9).

\subsection{Forced response in the GISS coupled atmosphere-ocean model ER simulations}

One hypothesis to explain the small but persistent circulation shifts in STD, put forward by our simulation with 
Fig. 9 Changes in the heat balance at the top of the atmosphere induced by the circulation changes between the MCA and the LIA. a Zonal mean of the difference in annual mean net incoming solar radiation at the top of the atmosphere $\left(\mathrm{W} \mathrm{m}^{-2}\right)$ between the sensitivity experiments in which the model is constrained to follow the atmospheric circulation simulated for the MCA (CirculMCA) and the LIA (CirculLIA), respectively (red), of the outgoing longwave radiation at the top of the atmosphere (green) and of the imbalance between incoming and outgoing radiations (blue). b Relative change in the zonal mean of the annual mean net incoming solar radiation at the top of the atmosphere between the conditions corresponding to the MCA and the LIA.

c Difference in annual mean net solar radiation at the surface $\left(\mathrm{W} \mathrm{m}^{-2}\right.$ ) between the conditions corresponding to the MCA and the LIA
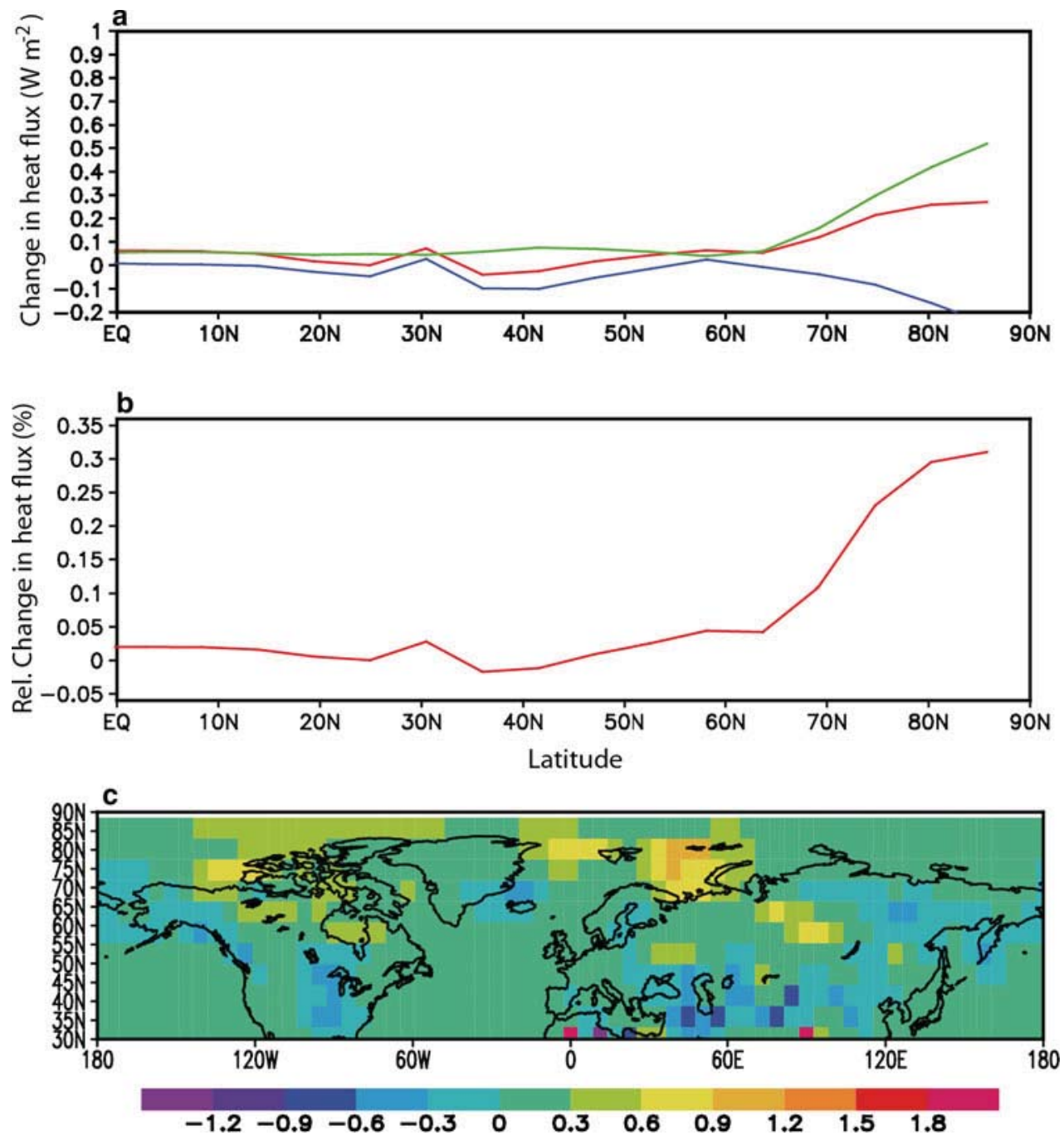

data assimilation, is intrinsic, internal variability of the extratropical climate system. Alternatively, the reconstructed extratropical variations could be induced by tropical sea surface temperature changes (Seager et al. 2007; Trouet et al. 2009; Burgman et al. 2010; Graham et al. 2011). Several studies have indeed shown that a slight warming of the tropical Indian and western Pacific oceans, and some cooling of the eastern Pacific (which are consistent with available reconstructions for the MCA but have still an uncertain origin) can induce teleconnections explaining many of the circulation and climate changes deduced from proxy records for the MCA. In particular, several aspects of Medieval hydroclimate, such as the prolonged drought in America, are well reproduced in models driven by such surface temperature changes in the tropics (Burgman et al. 2010; Graham et al. 2011). Unfortunately, this potential role of the tropics on extratropical climate cannot be studied in our framework, mainly because our model simulate an unrealistically weak response to tropical SST anomalies (Opsteegh et al. 1998). If such teleconnections leave an imprint in the midlatitudes, the anomalous circulation there can be selected by the particle filter among all the realisations of our ensemble but without being able to relate it to its tropical origin.

Another alternative hypothesis, alluded to in Mann et al. (2009) and in some earlier works (e.g. Shindell et al. 2001, 2003), is that the observed changes are a result of a shift in the probability distribution of internal modes of extratropical variability due to external forcing (see also Corti et al. 1999). We have investigated this latter hypothesis here in greater detail. We could not do so with LOVECLIM as the simulated response of the circulation to the forcing is too weak because of the simplifications applied in its representation of the atmospheric dynamics (Goosse and Renssen 2004; Goosse et al. 2010). By contrast, useful information on the potential role of the forcing in the circulation shifts can be derived from the results of the much 
a

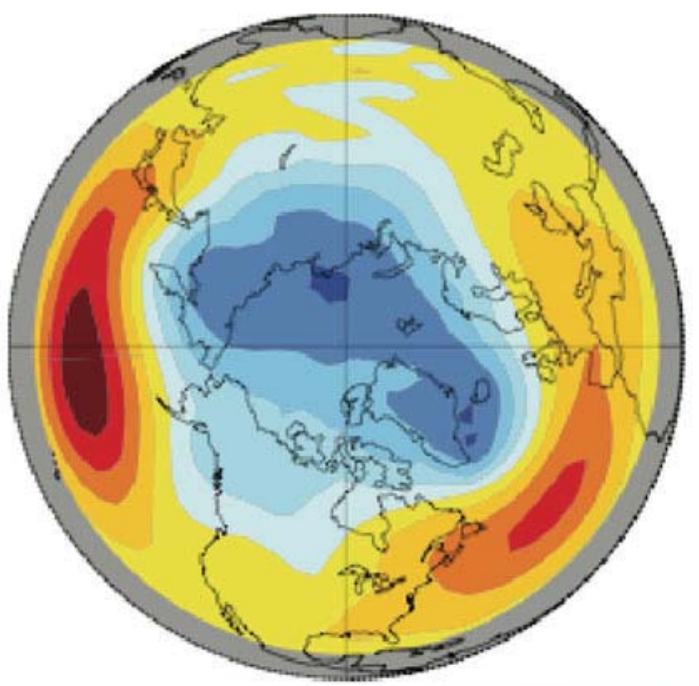

b

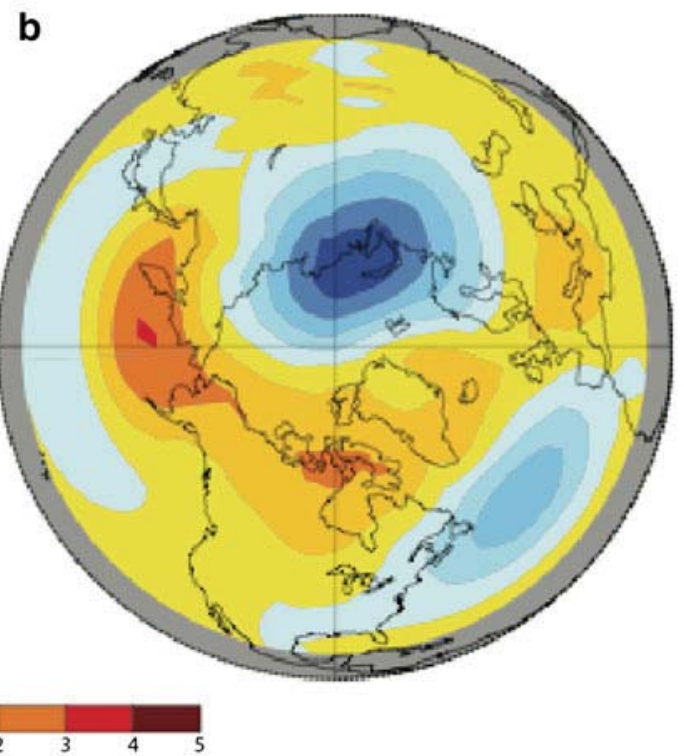

d
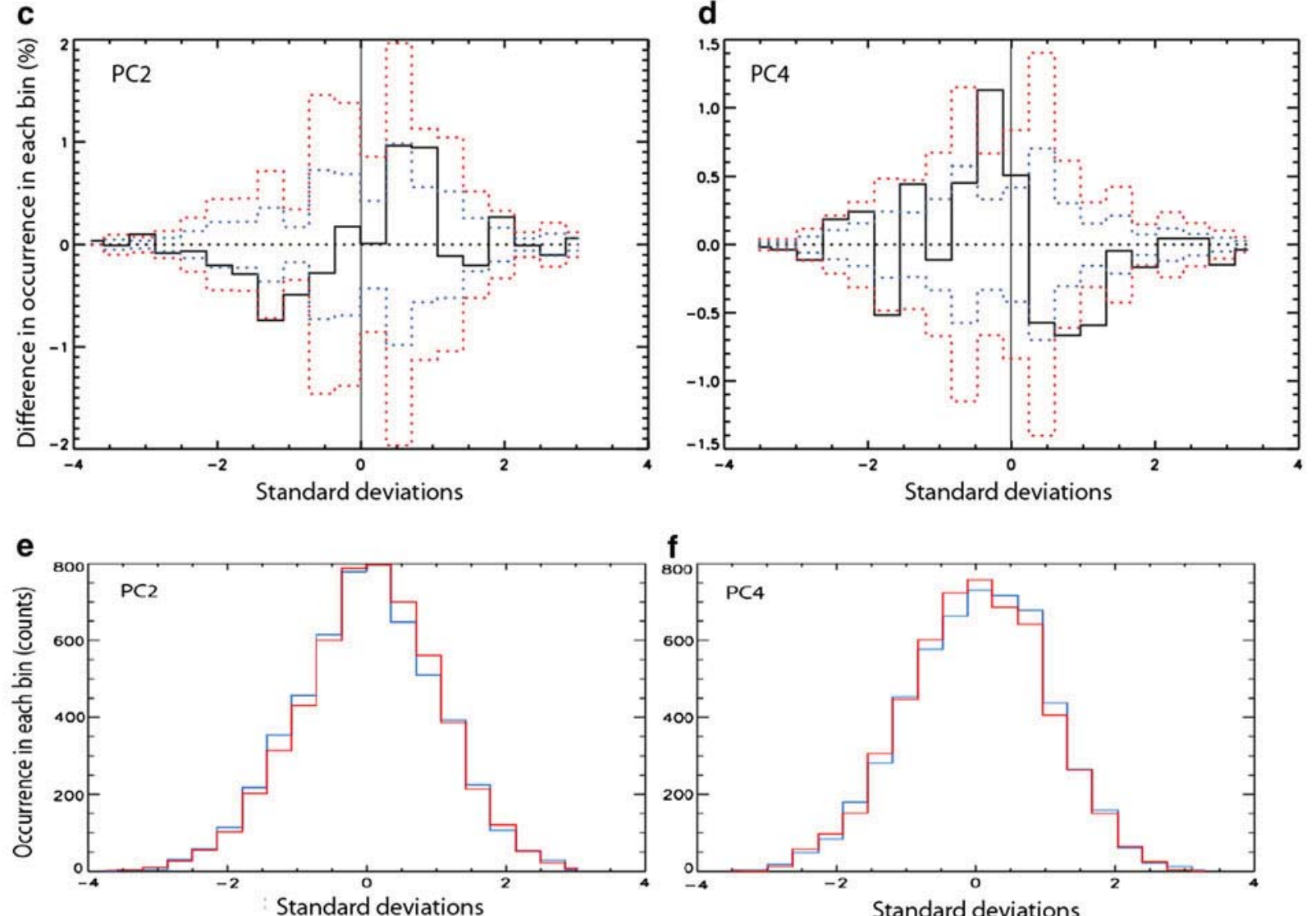

Fig. 10 Principal component analysis of the cold half year (November to April) sea level pressure in GISS-ER simulations over the past millennium. a The spatial pattern of the second eigenvector (associated with the time series of Principal Component PC2) and $\mathbf{b}$ of forth eigenvector (associated with PC4). c, d, the difference (in black) in the distribution of PC2 and PC4 between two periods of the MCA f

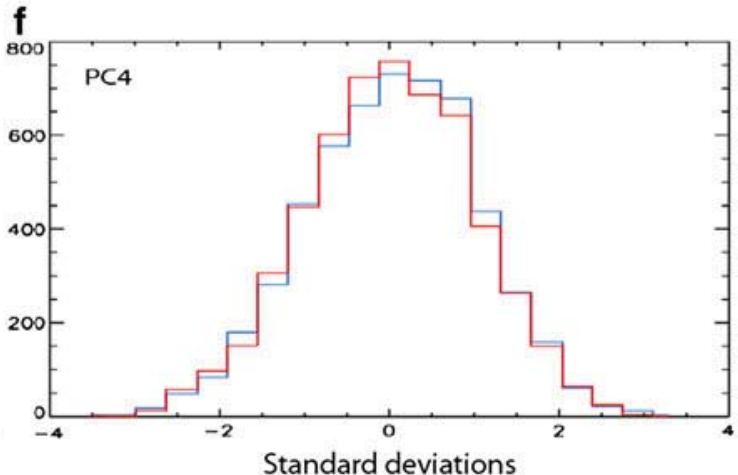

and LIA characterized by a strong difference in solar irradiance (in units of standard deviations). The full distribution is given on $\mathbf{e}, \mathbf{f}$ in red for the MCA and in blue for the LIA. The significance of the difference is evaluated by comparing it with one (in blue) and two (in red) standard deviations of this distribution using the same number of samples from a control run 
more sophisticated GISS-ER coupled atmosphere-ocean climate model by comparing its results during sub-periods of high and low solar irradiance during the MCA and LIA, respectively.

In the GISS-ER model, the solar forcing clearly shifts the probability distribution of the key extratropical atmospheric circulation modes as shown by an analysis of the leading principal components of sea level pressure (PCs, also commonly referred to as empirical orthogonal functions, or EOFs). The spatial pattern associated with the 2 nd ranked principal component ("PC2") displays a zonallysymmetric structure similar to the AO (Fig. 10a) but with a stronger centre of action in the Pacific. Its distribution is moved towards the positive phase (Fig. $10 \mathrm{c}$, e), while the more zonally-asymmetric 4th ranked PC ("PC4") (Fig. 10b) shifts towards the negative phase (Fig. 10d, f). The distribution of the other PCs, which could not be associated simply to any standard mode of atmospheric variability, is less influenced by the solar forcing.

Principal components 2 and 4 explain 21 and $8 \%$ of the variance, respectively. Furthermore, the shifts in their probability distribution are modest in comparison with the intrinsic internal variability. They are nonetheless responsible for a multi-decadal high surface pressure anomaly over the North Atlantic and North/Central Pacific and for a negative surface pressure anomaly at higher latitudes of about $60^{\circ} \mathrm{N}-70^{\circ} \mathrm{N}$. The associated circulation changes lead to significant temperature variations, as shown in Mann et al. (2009, see their Fig. 4). This clearly illustrates the potential role of such probability shifts induced by solar activity in the MCA-LIA transition.

\subsection{Role of the forcing in the MCA-LIA transition} compared to the twentieth century warming

In the standard simulation with data assimilation (STD), we assume that the uncertainty in the forcing can be represented by an additional forcing derived from a Gaussian distribution with a standard deviation of $0.4 \mathrm{~W} \mathrm{~m}^{-2}$. This may appear large compared to recent estimates (Schmidt et al. 2011), but such a high value can also be a way to represent the uncertainty in model response. For instance, if the model tends to underestimate the response to a forcing, the particle filter will likely select a particle with a stronger forcing in order to have a closer match between simulated and reconstructed temperature changes. Furthermore, there are still uncertainties in the exact magnitude of past changes in radiative forcing, in particular the
Fig. 11 Temperature changes in sensitivity experiments. a Anomaly of annual mean temperature $\left({ }^{\circ} \mathrm{C}\right)$ averaged over the region $30^{\circ} \mathrm{N}-60^{\circ} \mathrm{N}$ in the standard simulation with data assimilation (green) and in two sensitivity experiments in which no additional random forcing is applied (experiment Norandom, dark blue) and in which the standard deviation of the uncertainty of the forcing is assumed to be $0.8 \mathrm{~W} \mathrm{~m}^{-2}$ (experiment Random0.8, light blue). The reconstruction of Mann et al. (2009) is in red. The reference period is $1850-1980$. As in Fig. 1, the time series have been filtered using an 11-year Butterworth filter. The grey lines represent the range of the standard simulation with data assimilation (best estimate plus and minus two standard deviations). b Annual mean surface temperature difference between MCA (950-1250) and LIA (1400-1700) in Norandom. c The same as b but in Random 0.8
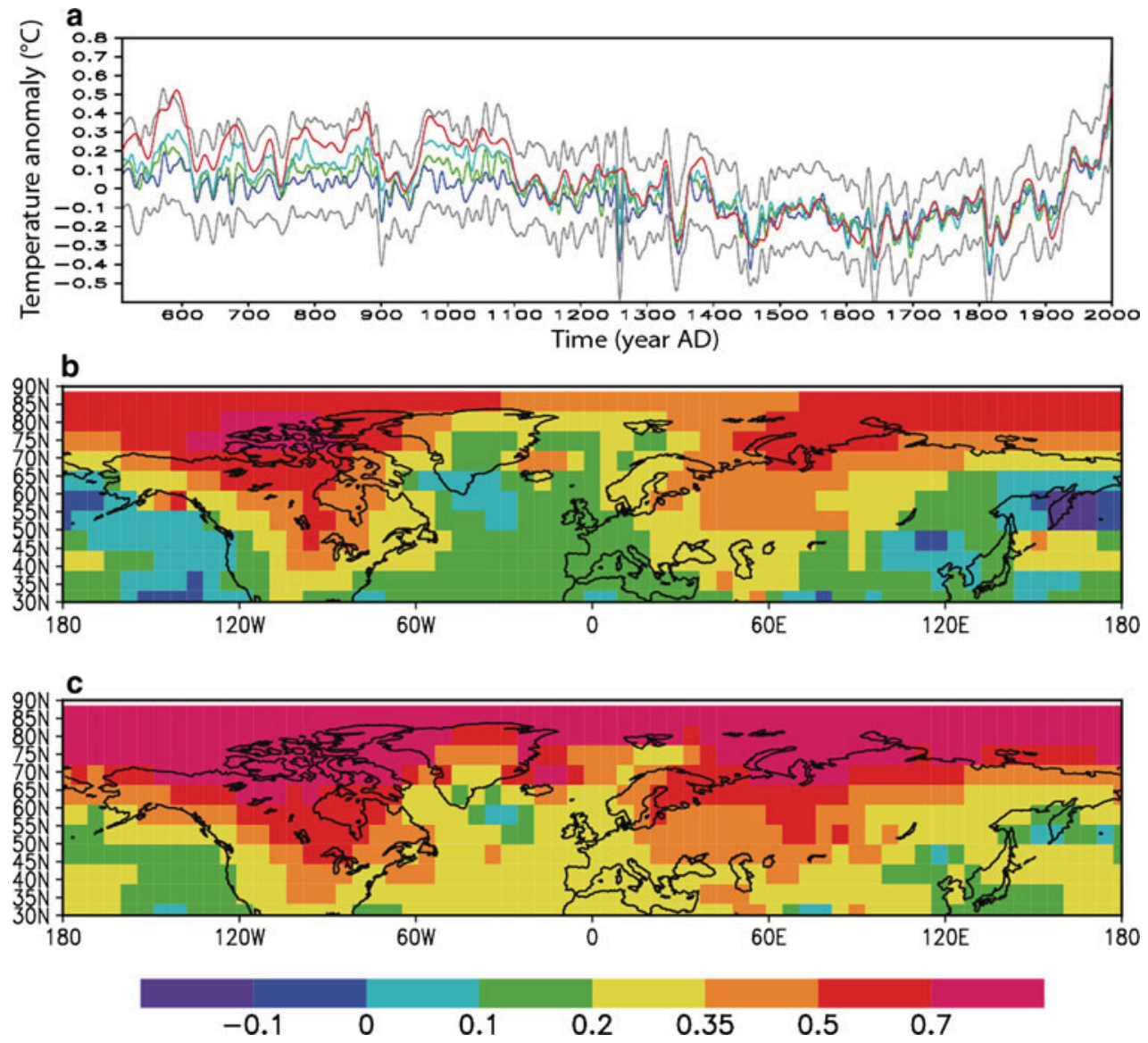
changes in solar irradiance that can justify such a high value (e.g. Schmidt et al. 2011; Shapiro et al. 2011).

In order to further analyze the role of such an additional forcing and to further highlight the way the data assimilation method works, we have compared the results of STD with the ones of two additional sensitivity experiments. In Norandom, already discussed above, no additional forcing is applied. In the second sensitivity experiment, we assume for the distribution of the additional forcing a very high standard deviation of $0.8 \mathrm{~W} \mathrm{~m}^{-2}$, to study the behaviour of the system in an extreme case (Random0.8).

As expected, because of the larger standard deviation of the forcing, the simulated temperature during the MCA increases in Random0.8, while it decreases in Norandom
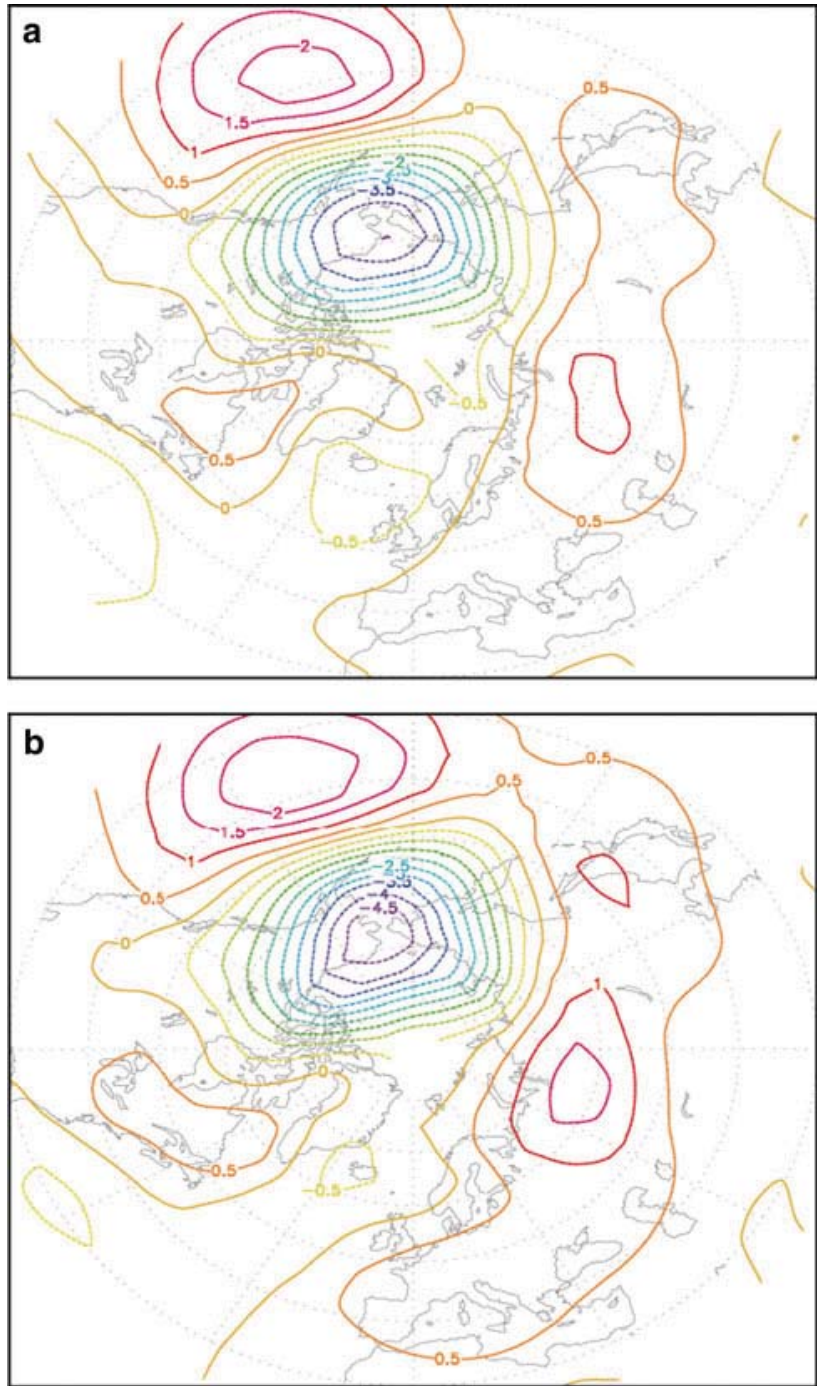

Fig. 12 Annual mean difference in geopotential height at $800 \mathrm{hPa}$ (in $m)$ between MCA (950-1250) and LIA (1400-1700) in additional model simulations with data assimilation. Compared to the standard experiment in a, no additional random forcing is applied (experiment Norandom) and in $\mathbf{b}$ the standard deviation of the uncertainty of the forcing is assumed to be $0.8 \mathrm{~W} \mathrm{~m}^{-2}$ (experiment Random0.8) compared to the STD. Nevertheless, the differences appear relatively small. For the LIA, the difference in annual mean temperature averaged over the region $30^{\circ} \mathrm{N}-60^{\circ} \mathrm{N}$ is smaller than $0.03^{\circ} \mathrm{C}$ between the three simulations (Fig. 11a). For the MCA, the range of the three simulations is $0.09^{\circ} \mathrm{C}$. Slightly larger differences appear for some periods, such as around $1000 \mathrm{AD}$, but even in that case the three experiments are relatively close to each other. The spatial temperature pattern is also similar in the three experiments, only with a higher large-scale warming in Random0.8 compared to STD and then in STD compared to Norandom (Fig. 11b, c). Furthermore, the changes in atmospheric circulation in all the experiments have the same characteristics (Fig. 12). This demonstrates that this pattern, which strongly contributes to the spatial structure of the warming during the MCA, is very robust in our experiments. This pattern also depends weakly on reasonable changes of the uncertainty assigned to the reconstruction (see "Appendix").

The larger warming is achieved in Random 0.8 thanks to a positive additional forcing of $0.2 \mathrm{~W} \mathrm{~m}^{-2}$ during the MCA and a negative one during the LIA of $0.14 \mathrm{~W} \mathrm{~m}^{-2}$ (Fig. 13). As expected, it appears thus also possible to explain the MCA-LIA transition using a larger forcing difference between those two periods than in Norandom and STD. Those values of the forcing, however, are quite high and incompatible with present best estimates because of the extreme hypothesis followed in Random0.8. Furthermore, the simulated changes in Random 0.8 are not strongly different from the ones obtained in Norandom and STD, and both experiments are compatible with the proxy based reconstruction within its own error bars. Consequently, there is no need to invoke a strong radiative forcing between the MCA and LIA to explain the reconstructed temperature changes. From the present estimates

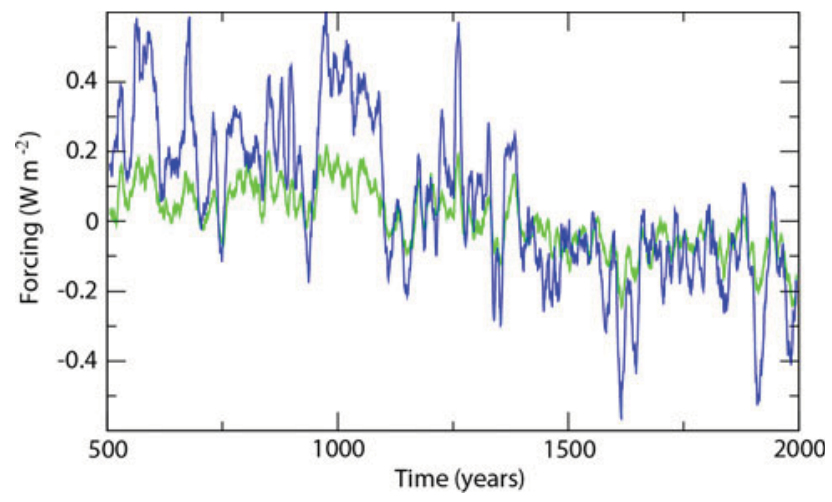

Fig. 13 Additional random forcing selected by the particle filter in the standard experiment with data assimilation (STD, in green) and in a sensitivity experiment in which the standard deviation of the uncertainty of the forcing is assumed to be $0.8 \mathrm{~W} \mathrm{~m}^{-2}$ (experiment Random0.8, in blue) 

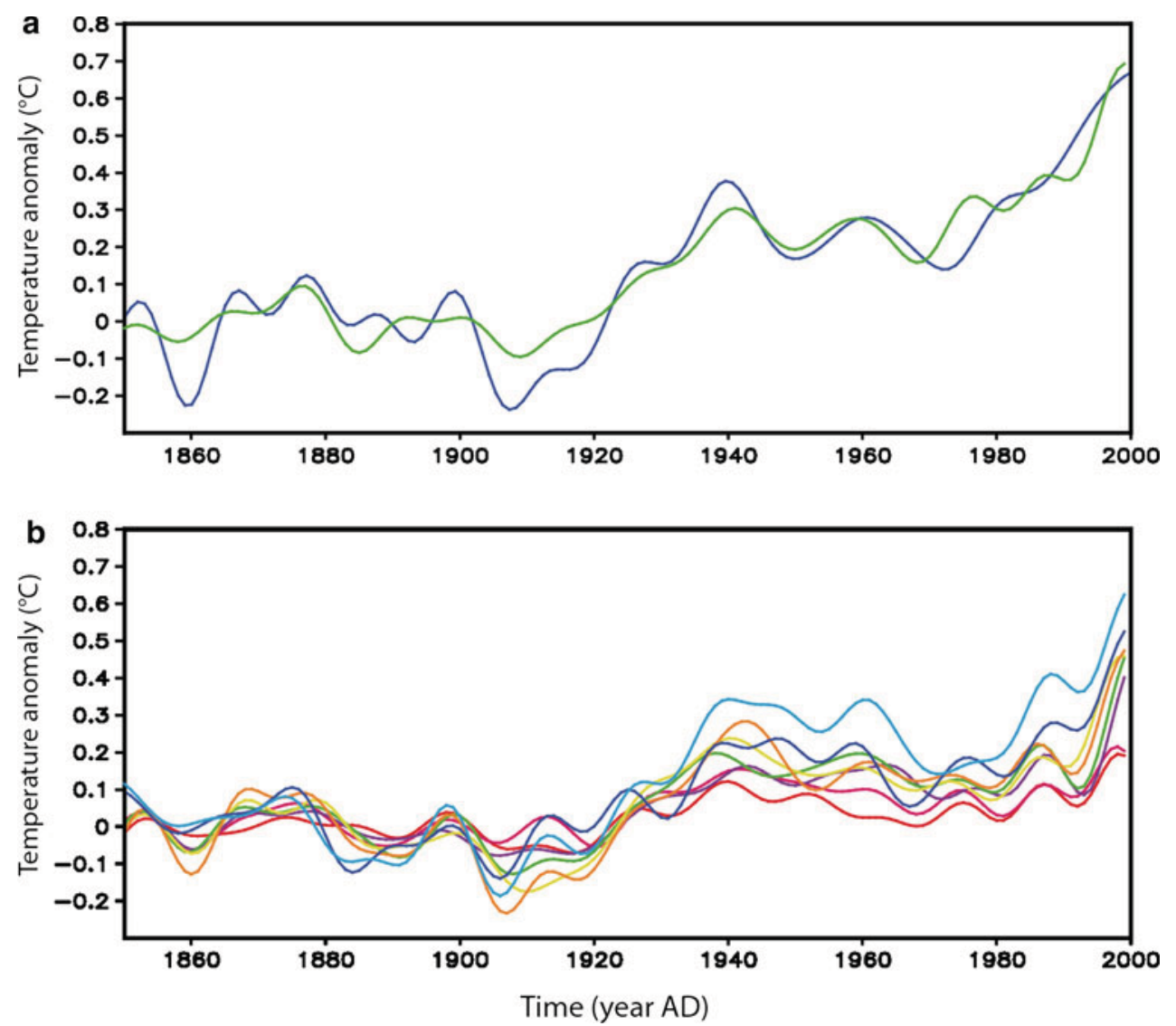

Fig. 14 Temperature over the past 150 years. a The anomalies of annual mean temperature $\left({ }^{\circ} \mathrm{C}\right)$ averaged over the region $30^{\circ} \mathrm{N}-60^{\circ} \mathrm{N}$ in the observations (Brohan et al. 2006, blue) and in the standard simulations with LOVECLIM with data assimilation using both natural and anthropogenic forcings (green). b The anomalies of annual mean temperature $\left({ }^{\circ} \mathrm{C}\right)$ averaged over the region $30^{\circ} \mathrm{N}-60^{\circ} \mathrm{N}$ in a group of simulations with data assimilation driven by a constant radiative forcing corresponding to pre-industrial conditions. In each of those experiments, we have assumed a different uncertainty of the forcing represented by a different standard deviation of the

of past forcing, we can rather conclude that the role of the forcing is very likely overestimated in Random0.8.

For the more recent past, the situation is different. When driven by a reasonable estimate of the changes in radiative forcing over the twentieth century, the simulation with data assimilation reproduces very well the observed warming (Fig. 14a). In order to evaluate the importance of this forcing, we have performed sensitivity tests using data assimilation over the period 1850-2000. In those experiments, in contrast to the standard one, the external forcing imposed to all the members is kept constant, corresponding to pre-industrial conditions. In addition to this common constant forcing, each ensemble member receives a different realization of a random forcing taken from a Gaussian distribution, as in the standard experiment with data assimilation. In the various experiments, the standard distribution of the random forcing applied for each particle: $0 \mathrm{~W} \mathrm{~m}^{-2}$ (red), $0.2 \mathrm{~W} \mathrm{~m}^{-2}$ (magenta), $0.4 \mathrm{~W} \mathrm{~m}^{-2}$ (violet), $0.8 \mathrm{~W} \mathrm{~m}^{-2}$ (green), $1.2 \mathrm{~W} \mathrm{~m}^{-2}$ (yellow), $1.4 \mathrm{~W} \mathrm{~m}^{-2}$ (orange). In addition, two experiments with data assimilation also driven by a constant radiative forcing corresponding to pre-industrial conditions but constrained to follow thermometer observations of Brohan et al. (2006) are also shown. In one experiment, the standard deviation of the additional random forcing is $0.8 \mathrm{~W} \mathrm{~m}^{-2}$ (dark blue) and in the other it is $1.2 \mathrm{~W} \mathrm{~m}^{-2}$ (light blue). The reference period is 1900-1950. The time series have been filtered using an 11-year Butterworth filter

deviation of this distribution ranges from 0 (no additional forcing) to $1.4 \mathrm{~W} \mathrm{~m}^{-2}$ (Fig. 14b).

When using a distribution for the random forcing with a small standard deviation, the forcing selected by the particle filter is also small (Fig. 15). As a consequence, it is not possible to reproduce the large warming observed over the last 50 years. When the standard deviation is smaller or equal to $0.2 \mathrm{~W} \mathrm{~m}^{-2}$, the late twentieth century is less than $0.2^{\circ} \mathrm{C}$ warmer than the second half of the nineteenth century, compared to an observed warming of more than $0.6^{\circ} \mathrm{C}$ over the region $30^{\circ} \mathrm{N}-60^{\circ} \mathrm{N}$ (Brohan et al. 2006). This means that, despite the data assimilation, it was not possible to find mechanisms internal to the system that could compensate for the absence of anthropogenic forcing.

When we consider a larger standard deviation of the distribution, the forcing selected by the filter increases 


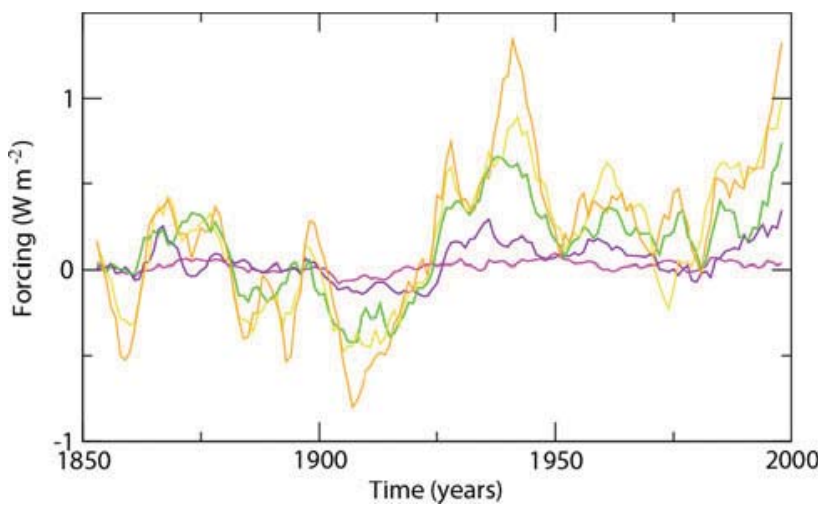

Fig. 15 Additional random forcing selected by the particle filter in experiments driven by a constant radiative forcing corresponding to pre-industrial conditions. In each of those experiments, we have assumed a different uncertainty of the forcing represented by a different standard deviation of the distribution of the random forcing applied for each particle: $0.2 \mathrm{~W} \mathrm{~m}^{-2}$ (magenta), $0.4 \mathrm{~W} \mathrm{~m}^{-2}$ (violet), $0.8 \mathrm{~W} \mathrm{~m}^{-2}$ (green), $1.2 \mathrm{~W} \mathrm{~m}^{-2}$ (yellow), $1.4 \mathrm{~W} \mathrm{~m}^{-2}$ (orange). An 11-year running mean has been applied to the time series

strongly. For the largest value, we reach at the end of the twentieth century a forcing of more than $1 \mathrm{~W} \mathrm{~m}^{-2}$, which is a bit lower than the best estimate of $1.6 \mathrm{~W} \mathrm{~m}^{-2}$ (Forster et al. 2007) but well in the range of uncertainty of this forcing. As a result, the temperature increases strongly during the twentieth century, in particular during the last decades, but the temperature is still lower than the observed one. We must keep in mind that in those experiments, we start from a highly biased estimate of the forcing, considering that the best prior estimate is a constant forcing and that positive and negative values over the twentieth century are as likely. This could partly explain the bias to low temperature in all those sensitivity experiments. The choice of the dataset selected for the data assimilation also has an impact. If we perform simulations with data assimilation constrained to follow the HADCRUT3 dataset (Brohan et al. 2006) as in Dubinkina et al. (2011), the bias becomes very small when the forcing is derived from a distribution using a large standard deviation (Fig. 14b). Finally, the range of those simulations with different estimates of the uncertainty of the radiative forcing is of $0.39^{\circ} \mathrm{C}$, i.e. at least 4 times more than in our experiments for the LIA and the MCA, even if we take into account the extreme case of experiment Random0.8.

We should insist that the goal of those sensitivity experiments was not to obtain an optimal reconstruction of the temperature or of the forcing over the twentieth century. In that case, it would be better to start from reasonable estimates of the forcing and of its uncertainty as in the standard experiment. We neither wanted to discuss specifically the dynamics of the recent temperature changes that have already been widely studied but rather to demonstrate the validity of our approach for a period when the role of the forcing is dominant. In our comparison between the twentieth century warming and the MCA-LIA transition, we must also acknowledge that data availability is much lower and the uncertainty of data is higher for the earlier periods. This has an impact on our estimation of the role of the forcing as more reliable estimates of the spatial temperature change or of the forcing would provide stronger constrains on our results and thus more precise conclusions.

\section{Conclusions}

We can conclude that it is possible to explain the reconstructed temperature changes during the MCA by a simple thermodynamic response to relatively weak changes in the forcing (of the order of $0.25 \mathrm{~W} \mathrm{~m}^{-2}$ between the MCA and the LIA in our simulation with data assimilation), combined with the influence of oceanic and atmospheric circulation changes. The first contributor, which sets up a general warming, can be captured simply by energy balance considerations. The latter one amplifies the warming and imposes its spatial structure. It is characterized in our experiments with data assimilation by stronger westerlies over mid latitudes, sharing thus some clear similarities with the positive phase of the $\mathrm{AO}$, as well as by a northward shift and an intensification of the western boundary current in the Pacific and, to a smaller extent, in the Atlantic.

Those circulation changes in LOVECLIM are mainly related to internal dynamics. The timing of the reconstructed changes can thus be reproduced by the model only if its development is directly constrained through data assimilation. The complementary results of the GISS-ER model suggest alternatively that the circulation shifts can be partly a consequence of the dynamical response to the radiative forcing. LOVECLIM, because of its simplified dynamics, would underestimate this forced contribution, compensating this bias by a stronger shift of the internal variability. Nevertheless, GISS-ER results were included here to discuss only qualitatively the potential mechanisms. Current uncertainties in the forcing and in the relevant physical processes preclude any definitive quantitative conclusions regarding the magnitude of this compensation in LOVECLIM, and thus it is still challenging to determine precisely the true role of internal versus external cause in the circulation changes.

Our results are based on the hypothesis chosen, in particular on our a priori estimate of the forcing and of its uncertainty. In our standard experiment, following the present-day knowledge, we have selected a relatively weak solar forcing and an uncertainty which may already appear large compared to some analyses. Nevertheless, experiments with an even larger uncertainty confirm that, as expected, the warm conditions during the MCA could also be explained as 
a response to a larger forcing change. This larger forcing does not presently provide the most likely hypothesis but may be kept in mind if new evaluations of the range of possible forcing variations are proposed in the future. But, even with this forcing, the circulation changes simulated in our simulation with data assimilation appear very robust.

Anyway, the transition between the MCA and the LIA, in which only a weak forcing is necessary to have results compatible with the reconstruction, contrasts with the recent decades for which a direct response to a much stronger radiative forcing is required to provide a satisfactory explanation for the observed large-scale warming (e.g. Hegerl et al. 2007). In our experiments, a forcing of the order of $1 \mathrm{~W} \mathrm{~m}^{-2}$ is needed to reproduce the recent warming, even with data assimilation. This indicates that our methodology was able to catch the different contributions of the forcing in these periods.

Acknowledgments We thank E. Zorita and R. Wilson for comments and all the scientists that collected and analysed the proxy data used in this work. H.G. is Senior Research Associate with the Fonds National de la Recherche Scientifique (FRS-FNRS-Belgium). This work is supported by the FRS-FNRS and by the Belgian Federal Science Policy Office (Research Program on Science for a Sustainable Development) and by EU (project Past4future). M.E.M. acknowledges support from the NSF Paleoclimate program (grant number ATM-0902133). Aurélien Mairesse helped in the design of Fig. 1. Computational resources have been provided by the supercomputing facilities of the Université Catholique de Louvain (CISM/ UCL) and the Consortium des Equipements de Calcul Intensif en Fédération Wallonie Bruxelles (CECI) funded by the Fond de la Recherche Scientifique de Belgique (FRS-FNRS).

\section{Appendix: Sensitivity to the uncertainty of the reconstruction}

The data assimilation methodology applied here provides estimates of the uncertainties. In addition, to test the validity of our conclusions, we have launched one supplementary simulation with data assimilation (Fig. 16) in which we use a slightly higher value for the uncertainty associated with the proxy-based reconstruction $\left(0.7^{\circ} \mathrm{C}\right.$ instead of $\left.0.5^{\circ} \mathrm{C}\right)$ (Experiment Uncertain0.7). For the mean temperature over the region $30^{\circ} \mathrm{N}-60^{\circ} \mathrm{N}$, the results of this new experiment are remarkably similar to the one of the standard simulation. The obtained spatial patterns of the temperature as well as the changes in atmospheric circulation (Fig. 17) are also in very close agreement to the ones described for the standard experiment. Locally, some small differences can be noticed,
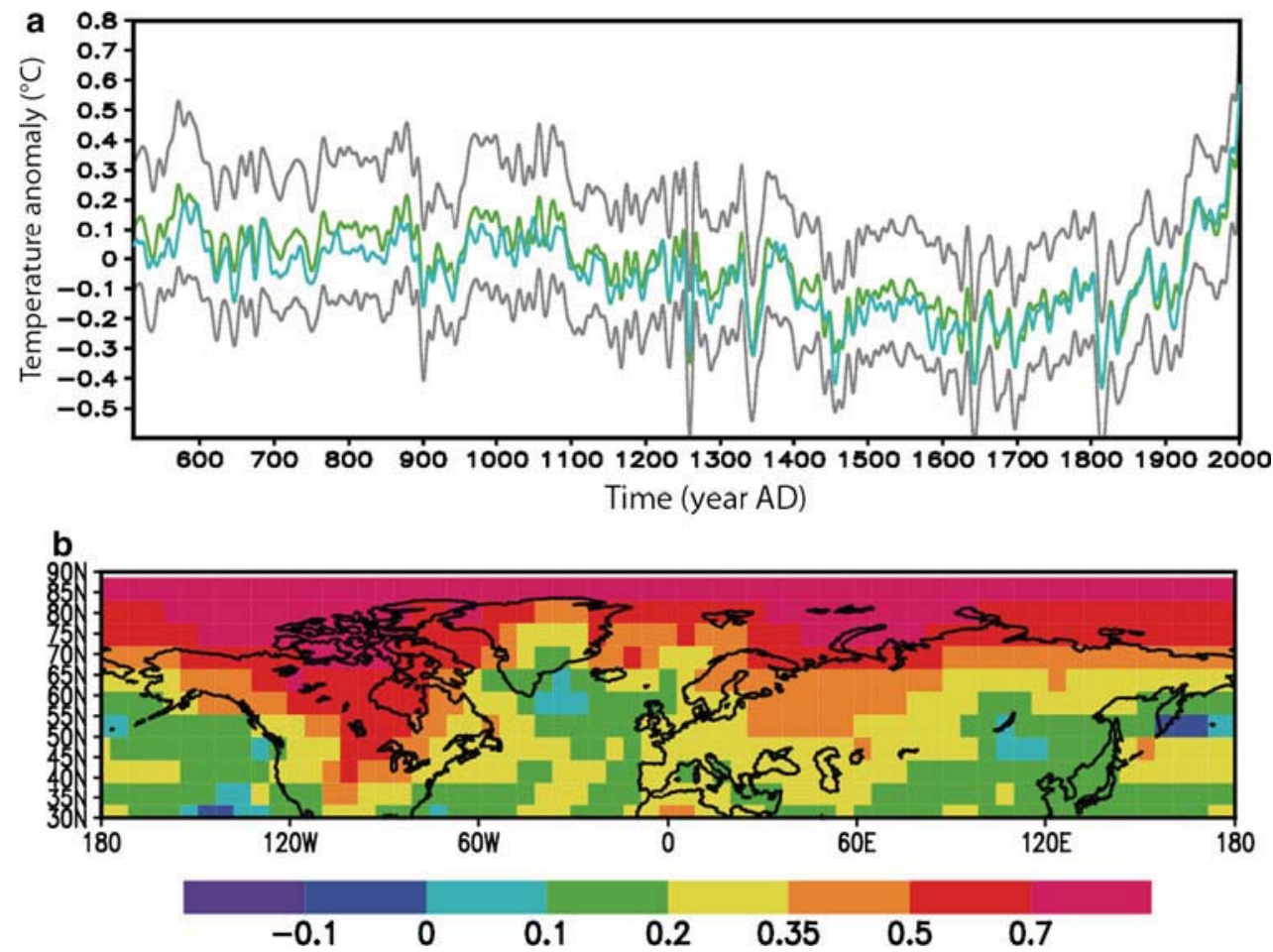

Fig. 16 Temperature changes in an additional model simulation with data assimilation in which, compared to the standard experiment, the uncertainty of the proxy-based reconstruction is assumed to be $0.7^{\circ} \mathrm{C}$ instead of $0.5^{\circ} \mathrm{C}$ (experiment Uncertain0.7). a Anomaly of annual mean temperature $\left({ }^{\circ} \mathrm{C}\right)$ averaged over the region $30^{\circ} \mathrm{N}-60^{\circ} \mathrm{N}$ in the standard simulation with data assimilation (green) and in Uncertain0.7 (light blue). The reference period is 1850-1980. As in Fig. 1, the time series have been filtered using an 11-year Butterworth filter. The grey lines represent the range of the standard simulation with data assimilation (best estimate plus and minus two standard deviations). b Annual mean surface temperature difference between MCA (950-1250) and LIA (1400-1700) in the experiment Uncertain0.7 


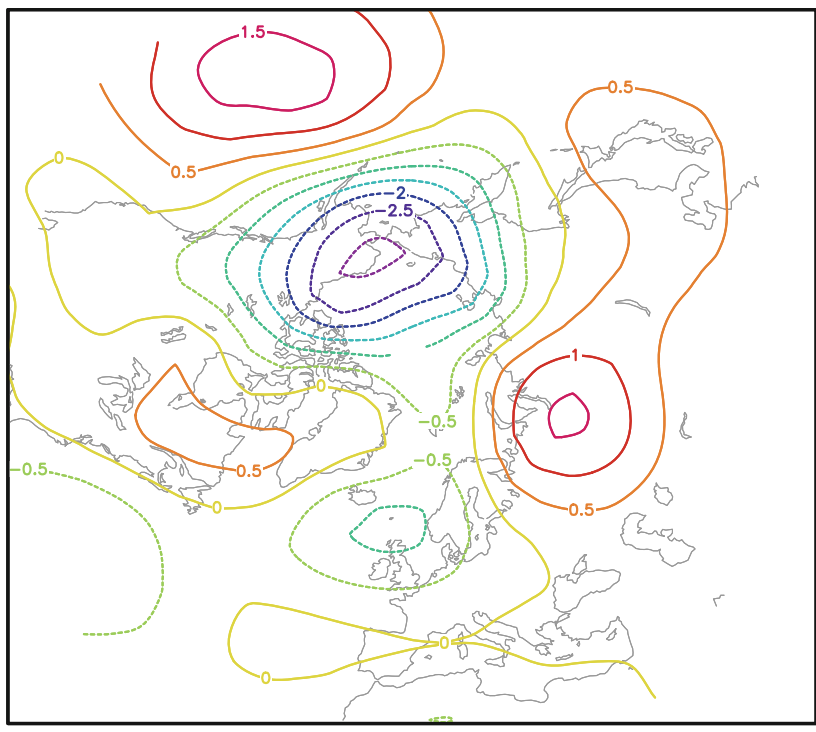

Fig. 17 Annual mean difference in geopotential height at $800 \mathrm{hPa}$ (in $\mathrm{m})$ between MCA (950-1250) and LIA (1400-1700) in the experiment Uncertain 0.7

but they are too small to challenge the interpretation deduced from the results of the standard simulation, illustrating that our results are robust at least when using the model and proxy based reconstruction applied here.

\section{References}

Ammann CM, Joos F, Schimel DS, Otto-Bliesner BL, Tomas RA (2007) Solar influence on climate during the past millennium: results from transient simulations with the NCAR climate system model. Proc Natl Acad Sci USA 104:3713-3718

Bard E, Raisbeck G, Yiou F, Jouzel J (2007) Comment on "Solar activity during the last $1000 \mathrm{yr}$ inferred from radionuclide records" by Muscheler et al. (2007). Quat Sci Rev 26:2301-2308

Berger AL (1978) Long-term variations of daily insolation and quaternary climatic changes. J Atmos Sci 35:2363-2367

Brohan P, Kennedy JJ, Harris I, Tett SFB, Jones PD (2006) Uncertainty estimates in regional and global observed temperature changes: a new data set from 1850. J Geophys Res 111:Art. No. D12106

Brovkin V, Bendtsen J, Claussen M, Ganopolski A, Kubatzki C, Petoukhov V, Andreev A (2002) Carbon cycle, vegetation and climate dynamics in the Holocene: experiments with the CLIMBER-2 model. Global Biogeochem Cycles 16. doi: 10.1029/2001GB001662

Burgman R, Seager R, Clement A, Herweijer C (2010) Role of tropical Pacific SSTs in global Medieval hydroclimate: a modeling study. Geophys Res Lett 37:L06705. doi:10.1029/2009 GL042239

Charlson RJ, Langner J, Rodhe H, Leovy CB, Warren SG (1991) Perturbation of the northern hemisphere radiative balance by backscattering from anthropogenic sulfate aerosols. Tellus 43 AB: $152-163$

Corti S, Molteni F, Palmer TN (1999) Signature of recent climate change in frequencies of natural atmospheric circulation regimes. Nature 398:799-802
Crowley TJ (2000) Causes of climate change over the past 1000 years. Science 289:270-277

Crowley TJ, Baum SK, Kim KY, Hegerl GC, Hyde WT (2003) Modeling ocean heat content changes during the last millennium. Geophys Res Lett 30:1932

Dubinkina S, Goosse H, Sallaz-Damaz Y, Crespin E, Crucifix M (2011) Testing a particle filter to reconstruct climate changes over the past centuries. Int J Bifurc Chaos (in press)

Esper J, Frank D (2009) The IPCC on a heterogeneous Medieval warm period. Clim Change 94:267-273

Forster P, Ramaswamy V, Artaxo P, Berntsen T, Betts R, Fahey DW, Haywood J, Lean J, Lowe DC, Myhre G, Nganga J, Prinn R, Raga G, Schulz M, Van Dorland R (2007) Changes in atmospheric constituents and in radiative forcing. In: Solomon S, Qin D, Manning M, Chen Z, Marquis M, Averyt KB, Tignor M, Miller HL (eds) Climate change 2007: the physical science basis. Contribution of Working Group I to the fourth assessment report of the Intergovernmental Panel on Climate Change. Cambridge University Press, Cambridge

Frank DC, Esper J, Raible CC, Buntgen U, Trouet V, Stocker B, Joos F (2010) Ensemble reconstruction constraints on the global carbon cycle sensitivity to climate. Nature 463:527-532

Frankignoul C, de Coetlogon G, Joyce T, Dong S (2001) Gulf Stream variability and ocean-atmosphere interactions. J Phys Oceanogr 31:3516-3529

González-Rouco F, von Storch H, Zorita E (2003) Deep soil temperature as proxy for surface air-temperature in a coupled model simulation of the last thousand years. Geophys Res Lett 30(21):2116

González-Rouco FJ, Fernández-Donado L, Raible CC, Barriopedro D, Luterbacher J, Jungclaus JH, Swingedouw D, Servonnat J, Zorita E, Wagner S, Ammann CM (2011) Medieval Climate Anomaly to Little Ice Age transition as simulated by current climate models. In: Xoplaki E, Fleitmann D, Diaz H, von Gunten L, Kiefer T (eds) Medieval Climate Anomaly. Pages News 19(1):7-8

Goosse H, Fichefet T (1999) Importance of ice-ocean interactions for the global ocean circulation: a model study. J Geophys Res 104:23337-23355

Goosse H, Renssen H (2004) Exciting natural modes of variability by solar and volcanic forcing: idealized and realistic experiments. Clim Dyn 23:153-163

Goosse H, Renssen H, Timmermann A, Bradley RS (2005a) Internal and forced climate variability during the last millennium: a model-data comparison using ensemble simulations. Quat Sci Rev 24:1345-1360

Goosse H, Crowley T, Zorita E, Ammann C, Renssen H, Driesschaert E (2005b) Modelling the climate of the last millennium: what causes the differences between simulations? Geophys Res Lett 32:L06710. doi:10.1029/2005GL22368

Goosse H, Renssen H, Timmermann A, Bradley RS, Mann ME (2006) Using paleoclimate proxy-data to select optimal realisations in an ensemble of simulations of the climate of the past millennium. Clim Dyn 27:165-184

Goosse H, Brovkin V, Fichefet T, Haarsma R, Jongma J, Huybrechts P, Mouchet A, Selten F, Barriat P-Y, Campin J-M, Deleersnijder E, Driesschaert E, Goelzer H, Janssens I, Loutre M-F, Morales Maqueda MA, Opsteegh T, Mathieu P-P, Munhoven G, Petterson E, Renssen H, Roche DM, Schaeffer M, Severijns C, Tartinville B, Timmermann A, Weber N (2010) Description of the earth system model of intermediate complexity LOVECLIM version 1.2. Geosci Model Dev 3:603-633

Graham NE, Ammann CM, Fleitmann D, Cobb KM, Luterbacher J (2011) Support for global climate reorganization during the 'Medieval Climate Anomaly'. Clim Dyn. doi:10.1007/s00382010-0914-z 
Gregory JM, Dixon KW, Stouffer RJ, Weaver AJ, Driesschaert E, Eby M, Fichefet T, Hasumi H, Hu A, Jungclaus JH, Kamenkovich IV, Levermann A, Montoya M, Murakami S, Nawrath S, Oka A, Sokolov AP, Thorpe RB (2005) A model intercomparison of changes in the Atlantic thermohaline circulation in response to increasing atmospheric $\mathrm{CO}_{2}$ concentration. Geophys Res Lett 32:L12703. doi:10.1029/2005GL023209

Hegerl GC, Stott PA, Allen MR, Mitchell JFB, Tett SFB, Cubasch U (2000) Optimal detection and attribution of climate change: sensitivity of results to climate model differences. Clim Dyn 16:737-754

Hegerl GC, Zwiers FW, Braconnot P, Gillett NP, Luo Y, Marengo Orsini JA, Nicholls N, Penner JE, Stott PA (2007) Understanding and attributing climate change. In: Solomon S, Qin D, Manning M, Chen Z, Marquis M, Averyt KB, Tignor M, Miller HL (eds) Climate change 2007: the physical science basis. Contribution of Working Group I to the fourth assessment report of the Intergovernmental Panel on Climate Change. Cambridge University Press, Cambridge

Hughes MK, Diaz HF (1994) Was there a "Medieval warm period", and if so, where and when? Clim Change 26:109-142

Hurrel JW (1995) Decadal trends in the North Atlantic oscillation: regional temperatures and precipitation. Science 269:676-679

Jones PD, Briffa KR, Osborn TJ, Lough JM, van Ommen T, Vinther BM, Luterbacher J, Zwiers FW, Wahl E, Schmidt G, Ammann C, Mann ME, Wanner H, Buckley BM, Cobb K, Esper J, Goosse H, Graham N, Jansen E, Kiefer T, Kull C, Mosley-Thompson E, Overpeck JT, Schulz M, Tudhope S, Villalba R, Wolff E (2009) High-resolution paleoclimatology of the last millennium: a review of the current status and future prospects. Holocene 19:3-49

Jungclaus JH, Lorenz SJ, Timmreck C, Reick CH, Brovkin V, Six K, Segschneider J, Giorgetta MA, Crowley TJ, Pongratz J, Krivova NA, Vieira LE, Solanki SK, Klocke D, Botzet M, Esch M, Gayler V, Haak H, Raddatz TJ, Roeckner E, Schnur R, Widmann H, Claussen M, Stevens B, Marotzke J (2010) Climate and carboncycle variability over the last millennium. Clim Past 6:723-737

Kalnay E (2003) Atmospheric modeling, data assimilation and predictability. Cambridge University Press, Cambridge

Korte M, Constable CG (2005) The geomagnetic dipole moment over the last 7000 years-new results from a global model. Earth Plan Sci Lett 236:348-358

Kwon Y-O, Alexander MA, Bond NA, Frankignoul C, Namamura H, Qiu B, Thomson LA (2010) Role of the Gulf Stream and Kuroshio-Oyashio systems in large-scale atmosphere-ocean interaction: a review. J Clim 23:3249-3281

Liu J, Chen R (1998) Sequential Monte Carlo methods for dynamical systems. J Am Stat Assoc 93:1032-1044

Ljungqvist FC (2010) A new reconstruction of temperature variability in the extra-tropical northern hemisphere during the last two millennia. Geografiska Annaler Ser A 92A:339-351

Lund DC, Lynch-Stieglitz J, Curry WB (2006) Gulf Stream density structure and transport during the past millennium. Nature 444:601-604

Mann ME, Rutherford S, Wahl E, Ammann C (2007) Robustness of proxy-based climate field reconstruction methods. J Geophys Res 112:D12109. doi:10.1029/2006JD008272

Mann ME, Zhang Z, Hughes MK, Bradley RS, Miller S, Rutherford S, Ni F (2008) Proxy-based reconstructions of hemispheric and global surface temperature variations over the past two millennia. Proc Natl Acad Sci 105:13252-13257

Mann ME, Zhang ZH, Rutherford S, Bradley RS, Hughes MK, Shindell D, Ammann C, Faluvegi G, Ni FB (2009) Global signatures and dynamical origins of the Little Ice Age and Medieval Climate Anomaly. Science 326:1256-1260

Miller RL, Schmidt GA, Shindell DT (2006) Forced annular variations in the 20th century Intergovernmental Panel on
Climate Change fourth assessment report models. J Geophys Res 111:D18101. doi:10.1029/2005JD006323

Muscheler R, Joos F, Beer J, Muller SA, Vonmoos M, Snowball I (2007) Solar activity during the last $1000 \mathrm{yr}$ inferred from radionuclide records. Quat Sci Rev 26:82-97

Opsteegh JD, Haarsma RJ, Selten FM, Kattenberg A (1998) ECBilt: a dynamic alternative to mixed boundary conditions in ocean models. Tellus 50A:348-367

Osborn TJ, Raper SCB, Briffa KR (2006) Simulated climate change during the last 1,000 years: comparing the ECHO-G general circulation model with the MAGICC simple climate model. Clim Dyn 27:185-197

Ramankutty N, Foley JA (1999) Estimating historical changes in global land cover: croplands from 1700 to 1992. Glob Biogeoch Cycles 13(4):997-1027

Sansó B, Foresty CE, Zantedeschiz D (2008) Inferring climate system properties using a computer model. Bayesian Anal 3(1):1-38

Schmidt GA, Jungclaus JH, Ammann CM, Bard E, Braconnot P, Crowley TJ, Delaygue G, Joos F, Krivova NA, Muscheler R, Otto-Bliesner BL, Pongratz J, Shindell DT, Solanki SK, Steinhilber F, Vieira LEA (2011) Climate forcing reconstructions for use in PMIP simulations of the last millennium (v1.0). Geosci Model Dev 4:33-45

Seager R, Graham N, Herweijera C, Gordon AL, Kushnir Y, Cook E (2007) Blueprints for Medieval hydroclimate. Quat Sci Rev 26:2322-2336

Servonnat J, Yiou P, Khodri M, Swingedouw D, Denvil S (2010) Influence of solar variability $\mathrm{CO}_{2}$ and orbital forcing between 1000 and $1850 \mathrm{AD}$ in the IPSLCM4 model. Clim Past 6:445-460

Shapiro AI, Schmutz W, Rozanov E, Schoell M, Haberreiter M, Shapiro AV, Nyeki S (2011) A new approach to long-term reconstruction of the solar irradiance leads to large historical solar forcing. Astron Astrophys 529:A67. doi:10.1051/0004$6361 / 201016173$

Shindell DT, Schmidt GA, Mann ME, Rind D, Waple A (2001) Solar forcing of regional climate change during the Maunder Minimum. Science 294:2149-2152

Shindell DT, Schmidt GA, Miller R, Mann ME (2003) Volcanic and solar forcing of climate change during the pre-industrial era. J Clim 16:4094-4107

Shindell DT, Faluvegi G, Schmidt GA, Miller RL, Hansen JE, Sun S (2006) Solar and anthropogenic forcing of tropical hydrology. Geophys Res Lett 33:L24706. doi:10.1029/2006GL027468

Swingedouw D, Terray L, Cassou C, Voldoire A, Salas-Mélia D, Servonnat J (2011) Natural forcing of climate during the last millennium: fingerprint of solar variability. Clim Dyn 36:1349-1364

Talagrand O (1997) Assimilation of observations, an introduction. J Met Soc Jpn. Special Issue 75, 1B:191-209

Trouet V, Esper J, Graham N, Baker A, Scourse JD, Frank DC (2009) Persistent positive North Atlantic Oscillation mode dominated the Medieval Climate Anomaly. Science 324:78-80

van Leeuwen PJ (2009) Particle filtering in geophysical systems. Mon Weather Rev 137:4089-4114

Wallace JM, Zhang Y, Renwick JA (1995) Dynamic contribution to hemispheric mean temperature trends. Science 270:780-783

Wang YM, Lean J, Sheeley NR (2005) Modeling the sun's magnetic field and irradiance since 1713. Astrophys J 625:522-538

Wanner H, Brönnimann S, Casty C, Gyalistras D, Luterbacher J, Schmutz C, Stephenson DB, Xoplaki E (2001) North Atlantic Oscillation-concepts and studies. Surv Geophys 22:321-382

Widmann M, Goosse H, van der Schrier G, Schnur R, Barkmeijer J (2010) Using data assimilation to study extratropical Northern Hemisphere climate over the last millennium. Clim Past 6:627-644 